\title{
Dual-Component Structural Plasticity Mediated by $\alpha$ CaMKII Autophosphorylation on Basal Dendrites of Cortical Layer 2/3 Neurones
}

\author{
Gillian Seaton, ${ }^{1}$ Gladys Hodges, ${ }^{1}$ Annelies de Haan, ${ }^{1}$ Aneesha Grewal, ${ }^{1}$ Anurag Pandey, ${ }^{1}$ Haruo Kasai, ${ }^{2}$ and ${ }^{D}$ Kevin Fox ${ }^{1}$ \\ ${ }^{1}$ School of Biosciences, Cardiff University, Cardiff CF10 3AX, United Kingdom, and ${ }^{2}$ Graduate School of Medicine, University of Tokyo, Tokyo 113-0033, \\ Japan
}

Sensory cortex exhibits receptive field plasticity throughout life in response to changes in sensory experience and offers the experimental possibility of aligning functional changes in receptive field properties with underpinning structural changes in synapses. We looked at the effects on structural plasticity of two different patterns of whisker deprivation in male and female mice: chessboard deprivation, which causes functional plasticity; and all deprived, which does not. Using 2-photon microscopy and chronic imaging through a cranial window over the barrel cortex, we found that layer $2 / 3$ neurones exhibit robust structural plasticity, but only in response to whisker deprivation patterns that cause functional plasticity. Chessboard pattern deprivation caused dual-component plasticity in layer $2 / 3$ by ( 1 ) increasing production of new spines that subsequently persisted for weeks and (2) enlarging spine head sizes in the preexisting stable spine population. Structural plasticity occurred on basal dendrites, but not apical dendrites. Both components of plasticity were absent in $\alpha$ CaMKII-T286A mutants that lack LTP and experience-dependent potentiation in barrel cortex, implying that $\alpha$ CaMKII autophosphorylation is not only important for stabilization and enlargement of spines, but also for new spine production. These studies therefore reveal the relationship between spared whisker potentiation in layer $2 / 3$ neurones and the form and mechanisms of structural plasticity processes that underlie them.

Key words: barrel cortex; CaMKII; dendrites; dendritic spine; experience-dependent plasticity; synaptic plasticity

Significance Statement

This study provides a missing link in a chain of reasoning that connects LTP to experience-dependent functional plasticity in vivo. We found that increases in dendritic spine formation and spine enlargement (both of which are characteristic of LTP) only occurred in barrel cortex during sensory deprivation that produced potentiation of sensory responses. Furthermore, the dendritic spine plasticity did not occur during sensory deprivation in mice lacking LTP and experience-dependent potentiation $(\alpha$ CaMKII autophosphorylation mutants). We also found that the dual-component dendritic spine plasticity only occurred on basal dendrites and not on apical dendrites, thereby resolving a paradox in the literature suggesting that layer $2 / 3$ neurones lack structural plasticity in response to sensory deprivation.

\section{Introduction}

Understanding the relationship between functional and structural plasticity requires knowing where in the brain the func-

\footnotetext{
Received Sept. 24, 2019; revised Dec. 30, 2019; accepted Jan. 3, 2020.

Author contributions: G.S., G.H., A.d.H., A.G., A.P., and K.F. performed research; G.S., G.H., A.d.H., and K.F. analyzed data; G.S., A.G., A.P., H.K., and K.F. edited the paper; H.K. and K.F. designed research; K.F. wrote the first draft of the paper; K.F. wrote the paper.

This work was supported by Medical Research Council MR/N003896/1, and Medical Research Council MR/ M501670/1 and Agency for Medical Research and Development (Strategic International Research Cooperative Program) for joint funding between the K.F. and H.K. laboratories. We thank Sam Barnes for critical reading of the manuscript.

The authors declare no competing financial interests.

Correspondence should be addressed to Kevin Fox at foxkd@cardiff.ac.uk.
}

tional plasticity takes place and then looking for the structural plasticity in that location. This issue is important for understanding processes underlying learning and memory. However, it is usually not possible to know where to look in the brain when plasticity is induced during learning because memories are distributed across networks of neurones within single brain structures, and even relatively simple learned behaviors involve multiple brain regions, any of which could house the sought-after structural changes (Hoffman and McNaughton, 2002; Josselyn and Frankland, 2018). From this viewpoint, understanding pla- 
Table 1. Basic statistics for the different groups of animals studied ${ }^{a}$

\begin{tabular}{|c|c|c|c|c|c|c|c|c|c|c|}
\hline Genotype & Deprivation & ROls & Mice & $\begin{array}{l}\text { Initial } \\
\text { spines }\end{array}$ & $\begin{array}{l}\text { Total } \\
\text { spines }\end{array}$ & $\begin{array}{l}\text { Age } \\
\text { range (d) }\end{array}$ & $\begin{array}{l}\text { Baseline } \\
\text { formation }\end{array}$ & $\begin{array}{l}\text { Baseline } \\
\text { elimination }\end{array}$ & $\begin{array}{l}\text { Peak formation } \\
\text { (deprived) }\end{array}$ & $\begin{array}{l}\text { Peak elimination } \\
\text { (deprived) }\end{array}$ \\
\hline WT & Undeprived & 15 & 5 & 478 & 715 & $70-125$ & 3.78 & 3.53 & - & - \\
\hline WT & Chessboard & 18 & 8 & 680 & 1501 & $75-107$ & 4.22 & 4.35 & 17.87 & 11.66 \\
\hline WT & $12 \mathrm{~h}$ chessboard & 4 & 1 & 88 & 180 & 63 & 3.86 & 3.42 & 31.58 & 25.72 \\
\hline WT & Chessboard (apical) & 7 & 2 & 203 & 317 & $74-87$ & 4.73 & 5.83 & 6.78 & 8.3 \\
\hline WT & All deprived & 12 & 6 & 292 & 595 & $86-116$ & 4.16 & 3.55 & 3.32 & 3.84 \\
\hline $\mathrm{T} 286 \mathrm{~A}$ & Undeprived & 11 & 4 & 438 & 932 & $91-104$ & 4.96 & 4.54 & - & - \\
\hline $\mathrm{T} 286 \mathrm{~A}$ & Chessboard & 13 & 5 & 382 & 787 & $86-131$ & 5.89 & 3.83 & 5.71 & 15.12 \\
\hline
\end{tabular}

${ }^{a}$ The number of ROls, animals, original spines at the first observation point, and total spines (new plus original) are given. The age range is for the start of the observation period and is in postnatal days. Baseline formation and baseline elimination rates are taken from the 2 or 3 baseline time points for the animals that will become deprived or across the entire observation period for undeprived cases. Formation and elimination values are expressed as percentages of the total number of spines present at the first time point and per day. All data are for basal dendrites, except where stated as apical.

sticity's structure-function relationship is more tractable when studied in sensory cortex and when induced by sensory deprivation because, in this case, the location of the functional plasticity is often well characterized.

Sensory deprivation causes functional plasticity in layer $2 / 3$ in visual and somatosensory cortex (Fox and Wong, 2005). Layer $2 / 3$ neurones increase their responses to sensory inputs spared from the deprivation and decrease their responses to sensory inputs that are deprived. Following whisker trimming in a chessboard pattern, layer $2 / 3$ neurones increase their responses to spared whisker stimulation and decrease their responses to deprived whisker stimulation (Wallace and Fox, 1999b). These changes are known to be cortical rather than subcortical and to depend on cortical activity (Fox, 1994; Wallace et al., 2001). Potentiation of the spared whisker response depends on autophosphorylation of CaMKII (Hardingham et al., 2003), which is a key step in induction of LTP (Giese et al., 1998; Chang et al., 2017). Depression of the deprived response is known to depend on GluA1 and to occlude LTD (Hardingham et al., 2008; Wright et al., 2008). These findings and others have implicated Hebbian processes in experience-dependent cortical plasticity (Glazewski and Fox, 1996; Glazewski et al., 2000; Wallace et al., 2001; Dachtler et al., 2011).

Although a great deal of work has been conducted on functional plasticity in layer $2 / 3$ cells, to date most studies on spine dynamics and structural plasticity in the cerebral cortex have been performed on layer 5 apical dendrites (Lendvai et al., 2000; Holtmaat et al., 2006; Wilbrecht et al., 2010; Keck et al., 2013). This can partly be explained by the availability of Thy-1 GFP lines, where the fluorophore is very conveniently expressed sparsely in a subset of layer 5 neurones and partly by the relative ease of imaging apical dendrites that lie close to the surface of the brain. However, functional plasticity in cortical layer 5 cells is complicated by the differences in plasticity mechanisms present in regular spiking and intrinsic bursting cells, whereas layer $2 / 3$ neurones appear more uniform in mechanism (Jacob et al., 2012; Greenhill et al., 2015). Furthermore, it is not clear how structural plasticity of apical dendritic spines might be related to functional changes in receptive fields, when most of the sensory input via thalamic and layer 4 projections to layer 5 neurones impinges on the basal, not the apical, dendrites (Petreanu et al., 2009). Even in layer $2 / 3$ neurones, the basal dendrites tend to receive strong sensory input from VPm and layer 4, whereas apical dendrites receive the input from motor cortex (Petreanu et al., 2009; Hooks et al., 2011). In this study, we have focused on structural plasticity in layer $2 / 3$ rather than layer 5 and on basal dendrites more than apical in an effort to rebalance these mismatches.

To understand structural changes related to potentiation mechanisms, we also compared the effect of whisker deprivation on plasticity in WTs with that in CaMKII autophosphorylation mutants that lack cortical and hippocampal LTP (Giese et al., 1998; Hardingham et al., 2003). Our findings elucidate the relationship between structural and functional plasticity in the cortex and demonstrate a pivotal role for CaMKII in both functional and structural plasticity.

\section{Materials and Methods}

Animals and rAAV constructs. We used male and female $\alpha$ CaMKIIT286A homozygous mutant mice, which have an alanine substituted at the threonine 286 location (Giese et al., 1998), and their WT littermates for imaging experiments (Table 1). Animals were social-group housed with ad libitum food and water in a 12:12 h normal light/dark cycle. All animal care and use procedures were performed in compliance with the UK Animals (Scientific Procedures) Act 1986. The rAAVs were purchased from the University of Pennsylvania Vector Core: rAAV2/1.CAG. FLEX.EGFP.WPRE.bGH (Allen Institute 854) and rAAV.CaMKII 0.4.Cre.SV40 (Allen Institute).

Transcranial window implantation and $r A A V$ intracranial virus injection. Cranial windows were implanted using methods similar to those published previously (Chen et al., 2000; Mostany and Portera-Cailliau, 2008; Holtmaat et al., 2009). Briefly, mice were injected with dexamethasone ( $2 \mathrm{mg} / \mathrm{g}$ body weight), deeply anesthetized with isoflurane, and head-fixed on an ultra-precise stereotaxic frame (Kopf Instruments, model 963). After shaving the hair, a midline incision of the scalp was made by scissors. The periosteum tissue was removed, the outer skin layers adhered to the skull with tissue adhesive (Vetbond, 3M), and the surgical steel head-plate was implanted with dental cement (Prestige Dental, Super Bond C+B kit). Mice were then head-fixed with the steel headplate, and areas were marked in the designated stereotactic coordinates for the D1 whisker of the barrel field $(3.0 \mathrm{~mm}$ lateral from midline and $1.5 \mathrm{~mm}$ posterior from bregma). A 3-mm-diameter craniotomy was performed using a micro drill. The skull was removed gently, and intact dura was covered with a drop of cortex buffer. Glass pipettes, tip diameter $10-20 \mu \mathrm{m}$ connected to an Ultra-microsyringe pump (WPI), and Micro4 controller (WPI) were lowered with a micropositioner (Kopf Instruments) to $200 \mu \mathrm{m} \mathrm{DV}$. The virus solution (200 nl) was injected slowly $(25 \mathrm{nl} / \mathrm{min})$ into the barrel cortex and was composed of virus solution (cre-AAV 1:10,000 in equal proportion with GFP-Flex 1:10) mixed with 10\% Fast Green for visualization. Sparse labeling was achieved by using low-titer cre-recombinase and high titer floxed GFP. ROIs were chosen at the edge of the virus diffusion radius (usually $150 \mu \mathrm{m}$ radius). The glass pipette was left for a further $2 \mathrm{~min}$ in the brain after injection had finished. In total, an injection was completed in $10 \mathrm{~min}$. A sterile $3 \mathrm{~mm}$ glass coverslip was placed over the exposed area and sealed with Super Glue and dental cement. Imaging began after a 2 to 3 week recovery period as described previously (Crowe and Ellis-Davies, 2014).

Sensory manipulation. For sensory deprivation experiments, whiskers of the facial pad contralateral to the cranial window were trimmed by a pair of scissors under a dissection microscope while the mice were under transient isoflurane anesthesia. Whiskers were subsequently trimmed 
A
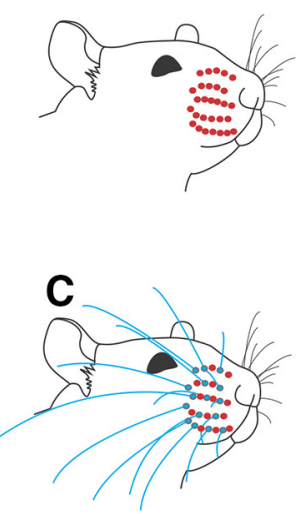

B

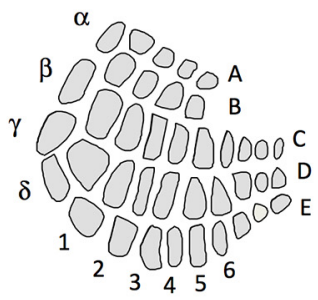

D

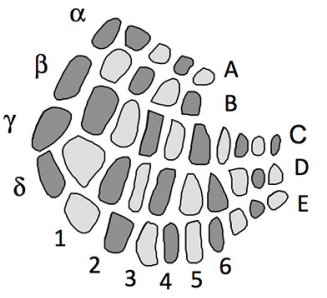

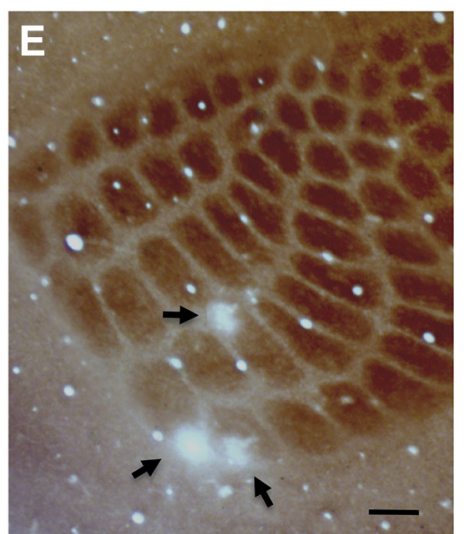

$\mathbf{F}$

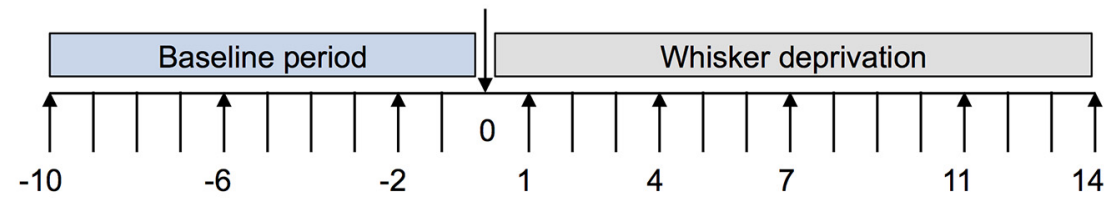

G Spine tracking (days)

H

Baseline (-2)

Post-deprivation (+7)
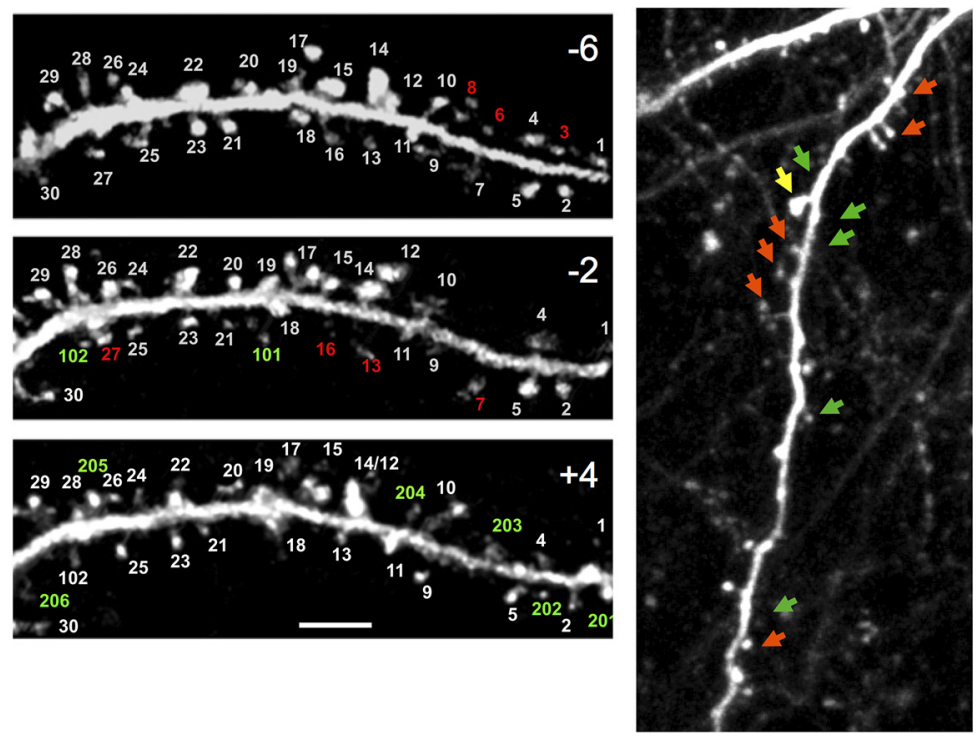

Figure 1. Whisker deprivation patterns and spine tracking. $\boldsymbol{A}$, Unilateral AWD, which produces $(\boldsymbol{B})$ uniform deprivation of all barrels in the cortex. $\boldsymbol{C}$, Unilateral $C$ WD produces (D), a chessboard pattern of active and deprived barrels whereby every barrel deprived of its principal whisker (light gray) is surrounded by four barrels that have their principal whisker intact (dark gray) and vice versa. $\boldsymbol{E}$, Photo-lesions are made in layer 4 of the barrel cortex on the last day of imaging (black arrows), to coregister the ROls within which spines are imaged with their corresponding home barrels. $F$, Imaging time points relative to deprivation on time point 0 were $-10,-6,-2,1,4,7,11$, and $14 \mathrm{~d}$. In some cases, 12 and $24 \mathrm{~h}$ time points were taken. $\mathbf{G}$, Spines are tracked over a period of days, shown here for $6 \mathrm{~d}$ before deprivation $(-6), 2 \mathrm{~d}$ before deprivation $(-2)$, and $4 \mathrm{~d}$ after deprivation (4). Spine number 17 is branched: such cases were counted as one spine. Some spines are eliminated from one time point to the next (red numbering); others are formed anew (green numbering). $\boldsymbol{H}$, Examples of eliminated (red arrows) and newly formed or enlarged spines (green arrows) shown for a dendrite imaged at $2 \mathrm{~d}$ before and $7 \mathrm{~d}$ after deprivation. Yellow arrow indicates a spine where the spine head shrinks over this period. Scale bars: $\boldsymbol{E}, 150 \mu \mathrm{m} ; \boldsymbol{G}, \boldsymbol{H}, 5 \mu \mathrm{m}$.

every other day for the duration of the imaging protocol. Whisker trimming for whole whisker pad deprivation involved trimming all whiskers (all whisker deprivation $[\mathrm{AWD}]$ ) from the contralateral facial pad (Fig. $1 A, B$ ), whereas chessboard pattern whisker deprivation (CWD) was performed with the D1 whisker always deprived and every other whisker cut with a pair of scissors in a chessboard pattern (Fig. 1C,D).

Two-photon imaging. For imaging sessions, animals were anesthetized lightly with isoflurane and head-fixed via the steel headplate under the objective lens. Two-photon imaging was performed with an Olympus
BX68 microscope and PrarieView software. All images were taken with $25 \times$ water-immersion objective (Olympus, W Plan-APOCHROMAT, 1.05 numerical aperture), $6 \mathrm{~mm}$ galvo mirrors, and a beam expander to ensure maximum illumination of the back aperture. A mode-locked Ti: sapphire laser (Chameleon Vision S, Coherent) was used to generate two-photon excitation $(900 \mathrm{~nm})$, with power at the back aperture in the range of $10-50 \mathrm{~mW}$. A pixel dwell time of $8 \mu \mathrm{s}$ with a frame size of $1024 \times$ 1024 pixels was used. Emission wavelengths were band-passed between $525-570 \mathrm{~nm}$, and the light path included an IR filter. Layer $2 / 3$ neurones 
were identified by imaging dendrites a minimum of $120 \mu \mathrm{m}$ from the brain surface, and where possible, tracing basal dendrites back to the cell soma and noting the depth. Dendritic spines on the basal dendrites of layer 2 and layer 3 cells (average depth of soma below dura: $222 \mu \mathrm{m}$, range: $175-375$ ) were imaged repeatedly every $3-4 \mathrm{~d}$ over a 3 week period before and after deprivation. Dendritic spine images were acquired in 1 $\mu \mathrm{m} z$ steps. Surface vasculature landmarks in combination with logged coordinates for each ROI were used for mapping and imaging the same region over the experimental time course. We aimed to image 10 ROIs from each animal over the period of 3-4 weeks. Two or three baseline images were taken separated by 3 or $4 \mathrm{~d}(-10,-6,-2 \mathrm{~d}$ relative to the day of deprivation at 0 ). Five postdeprivation time points were taken at 1 , 4, 7, 11, and 14 (Fig. $1 F$ ).

Photolesions. Mice were deeply anesthetized with isoflurane and headfixed under the $40 \times$ objective lens (Olympus, W Plan-APOCHROMAT $0.8 \mathrm{NA}$ water). An optical zoom of $\times 2$ was used, producing a $50 \mu \mathrm{m} \times 50$ $\mu \mathrm{m}$ FOV. The laser was mode-locked to a wavelength of $800 \mathrm{~nm}$ and the Pockels cell adjusted to deliver $\sim 50-64 \mathrm{~mW}$ power. Two-photon excitation was focused $400 \mu \mathrm{m}$ below the dura to lesion layer 4 . The galvos were centered and the shutter opened for a period of 10-12 min. Mice were then perfused under terminal anesthesia, and brain sections were stained for cytochrome oxidase to visualize the barrel field and photolesions demarcating the imaging field (Fig. 1E). Photo-lesions could be seen against the barrel field in horizontal section in layer 4 . In more superficial sections, the effect was apparent as regions of bleached fluorescence.

Image analysis. ImageJ was used to analyze all images. Raw image stacks were deconvolved using Fiji Deconvolution Lab plugin for ImageJ from point spread functions taken for the microscope and objective lens used. Images were only analyzed where the signal to background intensity was at least 4 . For dendritic spine analysis, dendritic spines were classified as a protrusion from the dendritic shaft at least $0.4 \mu \mathrm{m}$ (Holtmaat et al., 2009). The numbers of spines and dendrites imaged for each genotype and deprivation method can be found detailed in Table 1. Spine formation and elimination rates were calculated by counting the number of gained spines, lost spines, and total spines between each imaging session, per day for each dendrite (Fig. 1G,H). Formation rate was calculated by dividing the number of gained spines at each time point by the number of spines present at the first time point. The number formed per day was then calculated based on the interval between observation points. Elimination rate was calculated in an analogous way.

Bifurcating dendrites were chosen randomly in so far as they were not originally sought during image acquisition and were found to be the only ones in our sample that were relatively parallel to the FOV and satisfied our criterion for a bifurcation rather than a smaller offshoot branch. Dendritic width was measured at 3 points way from the bifurcation point and averaged. Where the two branch widths differed by $<15 \%$, we counted them as an even pair of branches.

Spine head size, neck width, and neck length were measured for each spine and used to classify spine types. Spine head width was taken as the greatest diameter across the spine head in the image in which it was in focus. Spines were only counted if they protruded at least $0.4 \mu \mathrm{m}$ from the dendrite. Spine head size distributions approximated a log-normal distribution when measured this way (Kolmogorov test), similar to the finding with other methods (Loewenstein et al., 2011). To estimate the error in measuring spine size, we took images of dendrites $30 \mathrm{~min}$ apart and cross-correlated the measures. The method assumes that the spines do not change size greatly over this time period. The average difference in size between observations was $<0.5 \%$ and ranged from $0 \%$ to $11 \%$ (mean $\pm \mathrm{SD} ; 0.04 \pm 0.10 \%, n=17$ ). The difference in size measured over 30 min was therefore $\sim 20$ times smaller than the average size increase seen with deprivation. The sum of the residuals for a linear regression fit $(y=1.013 x-0.03)$ was almost $0\left(6.2 \times 10^{-3}\right)$, suggesting no difference in the population.

We also classified spines according to the major types reported previously. Mushroom spines were defined as having a head size $>1.15$ times the neck width plus a neck length $<0.9 \mu \mathrm{m}$. Thin spines were counted as those having a head size $>1.15$ times the neck width and a neck length
$>0.9 \mu \mathrm{m}$. Stubby spines had a neck length $<0.9$ and a head size $<1.15$ times the neck width (in practice very similar neck and head width). We also saw a smaller number of filopodia, which were classified as having a head size $<1.15$ times the neck width, but neck length $>0.9 \mu \mathrm{m}$. Filopodia were not included in the spine analysis, except where stated in the spine classification sections.

Electrophysiology. Six C57BL/6J mice aged between P87 and P132 (average P104) were deprived of all their whiskers on one side of the snout for $1 \mathrm{~d}$, and 4 mice aged between P80 and P152 (average P111) were similarly whisker deprived for $7 \mathrm{~d}$. In addition, 6 mice were deprived in a chessboard pattern for $1 \mathrm{~d}$ (P84-P97, average P91) and 6 for $7 \mathrm{~d}$ (P92$\mathrm{P} 117$, average P103). A further 6 undeprived mice were recorded as controls (P75-P200, average P97). Animals were prepared for spike recording using carbon fiber microelectrodes under urethane anesthesia as described previously (Armstrong-James and Fox, 1987). Whiskers were acutely trimmed from the spared side of the snout and glued onto the whisker stubs on the deprived side using cyanoacrylate glue. Principal whisker responses were evoked by deflecting the whisker with a fast piezo-electric bimorph stimulator by a standard 1 degree deflection (10 $\mathrm{ms}$ ). Responses were averaged over 50 stimuli and defined as spikes produced during a 3-53 ms following stimulation. Details of recording methods can be found previously (Fox, 1992; Fox et al., 2018). Mice were perfused with PFA and cryoprotected with sucrose before the brains were flattened for sectioning using a freezing microtome. Sections were reacted for cytochrome oxidase to view the electrolytic lesions made after each recording penetration and thereby establish the principal barrel for each recording penetration and the depth of recording for each cell. Neurones were identified as layer $2 / 3$ or layer 4 , and the ratio of the average layer $2 / 3$ to layer 4 response was calculated for each animal. Group averages were calculated for $1 \mathrm{~d}$ deprived and $7 \mathrm{~d}$ deprived animals and compared with published values for young animals (P28-P53) receiving all whisker deprivation for 1 or $7 \mathrm{~d}$.

Experimental design and statistical analysis. The experimental design was longitudinal for spine imaging studies comprising 2 or 3 baseline time points followed by 5 time points over a further 2 weeks of repeatedly imaging the same locations. This allowed us to apply paired $t$ tests to compare all possible baseline and postdeprivation time point combinations. Three variants of this statistical approach were planned: one to study another genotype, CaMKII-T286A mice using chessboard deprivation; the other two, to study the effects of whisker deprivation, namely, undeprived mice with "chessboard-deprived" and "all whisker deprived" mice. Male and female mice were studied for all groups. The ratio of male to female mice was $\sim 3: 2$, respectively, in the final sample, due to slightly fewer female mice in the CaMKII-T286A group reaching the weight required for recovery surgery (as stipulated by the animal care legislation under which we operate). We planned to image 10 ROIs for each animal (for summary statistics, see Table 1). However, due to the long period of imaging and the fact that basal dendrites were located deeper than those conventionally studied on apical dendrites, not all ROIs remained sufficiently clear over the full 3 week period. On average, $\sim 3$ ROIs remained clear per animal over the full 3 week period (7 or 8 observations for each ROI).

Spine size changes were analyzed using matched-pair $t$ tests as described in Results and, where unmatched populations were studied, by ANOVA methods. Spine head sizes were found to be log-normal as described previously (Loewenstein et al., 2011), and were therefore logtransformed before using parametric methods. In 1 case (transient spines in CaMKII-T286A mice), the data were not normally or log-normally distributed and nonparametric tests were used. Spine categorization analysis and spine lifetime measures were analyzed using nonparametric tests (Wilcoxon signed rank and $\chi^{2}$ methods). Cross-correlations were assessed using linear regression analysis. Data were analyzed using JMP software (SAS).

Precautions were taken against unintended bias: the images were (1) analyzed blind to the hypothesis and/or (2) analyzed by more than one person and cross-checked and/or (3) analyzed blind to the genotype. In addition, in all cases, a different person from the one collecting and measuring the images performed statistical analysis on the data. 


\section{A Undeprived}

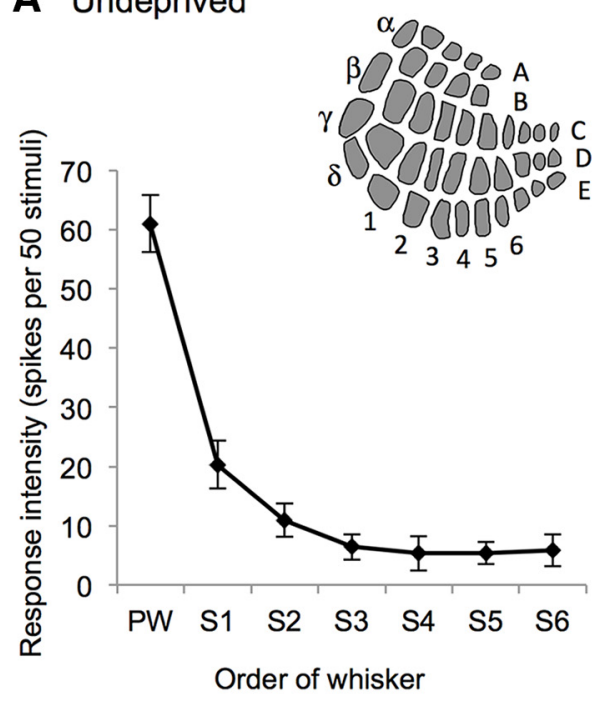

Chessboard: Deprived barrels

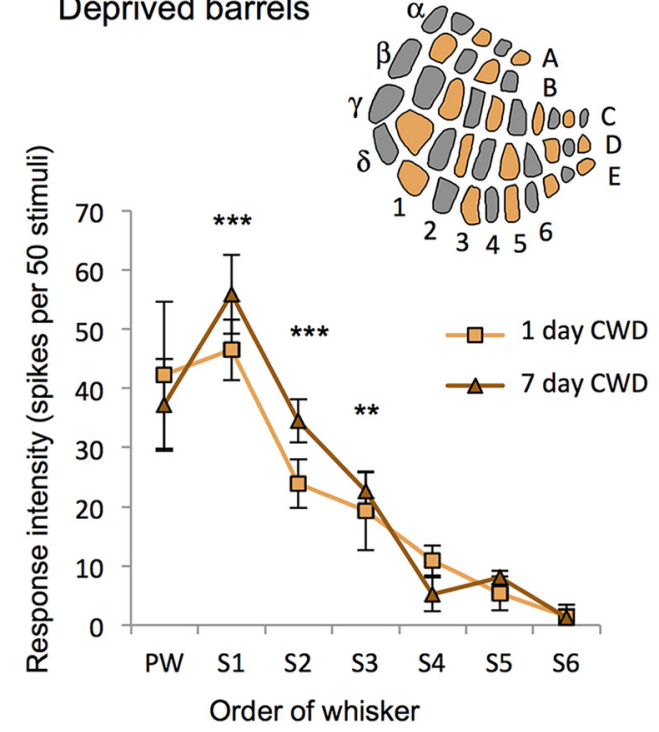

\section{B All deprived}

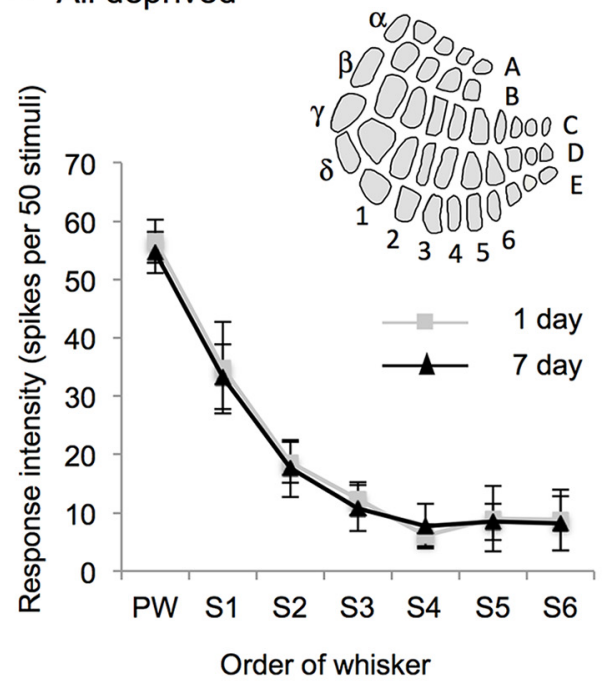

D Chessboard: Spared barrels

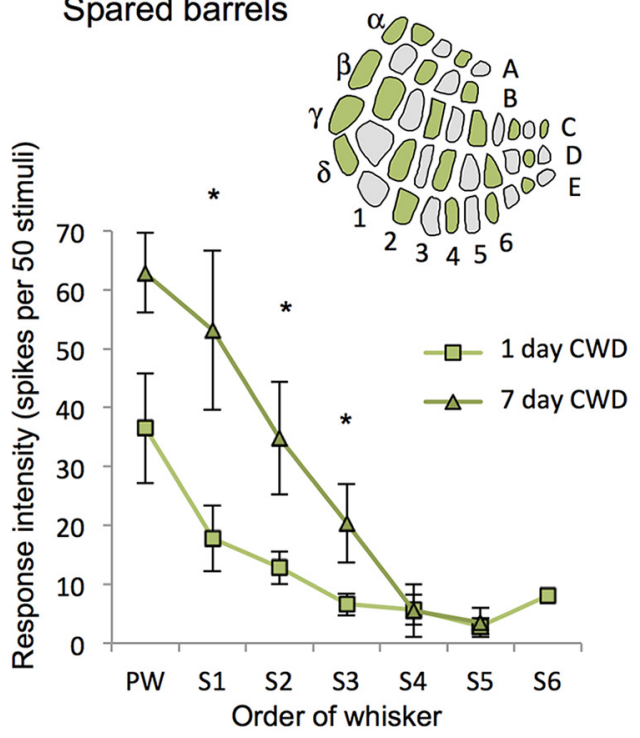

Figure 2. Effect of deprivation pattern on receptive field properties. A, Principal whisker and surround receptive field (SRF) whiskers are plotted against the response evoked in layer $2 / 3$ averaged across animals. SRF responses are ranked for each cell $(S 1, S 2 \ldots S 6)$ before averaging across cells for each animal. Inset, Diagram of barrel field indicates all barrels receive principal whisker input (dark gray). B, Receptive field properties are unchanged in animals unilaterally deprived of all their whiskers at $1 \mathrm{~d}$ (gray) and $7 \mathrm{~d}$ (black) postdeprivation. Inset, Diagram of barrel field shows all barrels are deprived of principal whisker input (light gray). C, Receptive fields in barrels deprived of principal whisker input are altered by CWD. In deprived barrels, spared surround whisker responses (S1-S6) increase, whereas principal whisker (PW) responses decrease. Inset, Diagram of barrel field shows that barrels deprived of their principal whisker (orange) alternate with barrels with their spared whisker intact (dark gray). D, Receptive fields in barrels with spared principal whiskers also show an increase in surround whisker responses at $7 \mathrm{~d}$ but not $1 \mathrm{~d}$. Inset, Green represents spared barrels. Light gray represents deprived barrels. ${ }^{* *} p<0.001 .{ }^{* *} p<0.01 .{ }^{*} p<0.05$. Stars indicate statistical difference from undeprived case plotted in $\boldsymbol{A}$.

Electrophysiological data were analyzed by averaging neuronal responses to standard whisker deflections for all cells in a given layer for each animal and then averaging values across animals within the treatment/time point group. Comparisons between groups were then made using ANOVA followed by post hoc $t$ tests where appropriate. Population data for formation and elimination rates were also analyzed using ANOVA followed by post hoc $t$ tests where effects were detected.

\section{Results}

The effect of whisker deprivation pattern on receptive field plasticity

We compared the effects of CWD and AWD on receptive field plasticity in layers $2 / 3$ of the barrel cortex in young adult mice (average age $\mathrm{P} 100$ ).
$A W D$

Depriving all the whiskers uniformly for 1 or $7 \mathrm{~d}$ did not cause potentiation of any surround receptive field whisker $\left(F_{(2,2)}=\right.$ $1.16, p=0.32)$, nor indeed change any receptive field component at all (Fig. 2A,B). While depriving all the whiskers can cause depression of deprived whisker responses in younger animals (Glazewski et al., 2017), we found it did not produce any change in the receptive fields of the older animals studied here (average age $107 \mathrm{~d}$, range 80-152 d). The principal whisker response appeared to decrease marginally (to $90 \%$ of undeprived values) but was not found to be significantly different from control values $\left(F_{(1,16)}=1.44, p=0.25\right)$. 


\section{CWD}

In contrast, CWD did cause substantial potentiation of spared whisker responses, both in the barrel columns where the principal whisker had been deprived $\left(F_{(2,2)}=18.66, p<0.001\right.$; Fig. $\left.2 C\right)$ and in the spared barrel columns where the principal whisker had been spared $\left(F_{(2,2)}=5.26, p<0.01\right.$; Fig. $\left.2 D\right)$. In deprived barrels, the three strongest surround receptive field whisker responses potentiated twofold to threefold after a single day of deprivation $(\mathrm{S} 1, \times 2.23$; S2, $\times 2.14$; $33, \times 3.03)$ and increased further by $7 \mathrm{~d}$ $(\mathrm{S} 1, \times 2.75 ; \mathrm{S} 2, \times 3.16$; $\mathrm{S} 3, \times 3.53)$. In spared barrels, there was a delay to the potentiation, which occurred after $7 \mathrm{~d}$, again for the three strongest surround receptive field whiskers $(\mathrm{S} 1, \times 2.62 ; \mathrm{S} 2$, $\times 3.18 \mathrm{~S} 3, \times 2.91)$. We also found that principal whisker responses fell to $65 \%$ of control values $1-7 \mathrm{~d}$ following CWD and were significantly different from responses in control undeprived mice $\left(F_{(1,20)}=6.18, p<0.03\right)$.

The difference in effects of CWD and AWD are summarized in Figure $3 A, D$, which shows principal whisker responses and the strongest surround whisker responses (S1) for control, 1 and $7 \mathrm{~d}$ deprived mice.

\section{The effect of whisker deprivation pattern on spine formation and elimination}

To determine whether structural plasticity occurred in layer $2 / 3$ neurones and to see whether it was related to receptive field plasticity observed in layer $2 / 3$ neurones, we repeated the two whisker deprivation patterns in mice prepared with cranial windows for imaging dendritic spines.

\section{$A W D$}

We compared the rate of spine formation and elimination in AWD mice with their predeprivation baseline rates and found that formation and elimination were unchanged $24 \mathrm{~h}$ after deprivation (baseline vs formation at day 1: $t_{(10)}=0.45, p<0.65$; baseline vs elimination at day 1: $t_{(9)}=0.40, p<0.69$; paired $t$ tests) (Fig. $3 B, C$ ). Similarly, formation and elimination rates were not different from those seen in undeprived animals at any time point (no effect of deprivation on formation $F_{(1,137)}=0.068$, $p=0.79$, or elimination $F_{(1,130)}=0.77, p=0.38$; two-way ANOVA). This finding is consistent with the lack of functional plasticity found with this deprivation pattern at these ages (Fig. $3 A$ ) and suggests that spine dynamics are unaffected by a general loss of afferent drive.

\section{$C W D$}

We compared rates of dendritic spine formation and elimination in WT mice that had their whiskers deprived in a chessboard pattern with their predeprivation baseline rates. We found that formation and elimination increased significantly following $24 \mathrm{~h}$ of deprivation (formation: baseline vs $24 \mathrm{~h}$ deprivation: $t_{(17)}=$ 8.75, $p<0.0001$; elimination baseline vs $24 \mathrm{~h}$ deprivation: $t_{(17)}=$ $5.10, p<0.0001$; paired $t$ tests) (Fig. $3 E$ ). To quantify the effect, we compared baseline formation and elimination rates in mice without whisker deprivation over a similar period of time. In undeprived mice at this age $(70-125 \mathrm{~d})$, we found that baseline formation and elimination rates were evenly matched, comprising $\sim 4 \%$ of the original spines per day (Fig. $3 E$ ). The effect of whisker deprivation was to increase transiently the formation rate to $18 \%$ and the elimination rate to $12 \%$. The formation rate then remained elevated above baseline over the succeeding $14 \mathrm{~d}$, although at a far lower rate than that observed on the first day (Fig. 3E,F). Repeated-measures ANOVA showed a significant two-way interaction between time and deprivation for spine formation in WT mice $\left(F_{(5,163)}=31.35, p<0.0001\right)$. When ana- lyzed per time point, the formation rate was significantly elevated on days 1,4 , and $11\left(F_{(1,32)}=55.93, p<0.0001\right.$ on day $1, F_{(1,31)}=$ $13.15, p<0.001$ on day $4, F_{(1,25)}=13.51, p=0.005$ on day 11$)$ (Fig. 3E).

Elimination rates also remained elevated during CWD, meaning that only a small net gain in spines occurred over the 2 week period (Fig. 3E). Once again, a repeated-measures ANOVA showed a significant two-way interaction between time and deprivation for WT mice $\left(F_{(5,160)}=6.52, p<0.0001\right)$. Analyzed per time point, spine elimination was significantly elevated $1,4,7$, and $11 \mathrm{~d}$ following deprivation $\left(F_{(1,32)}=22.91, p<0.0001\right.$ on day $1, F_{(1,31)}=4.77, p<0.05$ on day $4, F_{(1,30)}=7.34, p<0.05$ on day $7, F_{(1,22)}=9.51, p<0.01$ on day 11 ) (Fig. $3 E$ ). These results show that whisker deprivation patterns that cause functional plasticity (CWD) also cause structural plasticity in layer $2 / 3$ neurones, whereas whisker deprivation patterns that do not cause functional plasticity (AWD) leave no trace of structural plasticity.

Previous studies have demonstrated that new spines tend to form on a particular subset of dendritic branches that exhibit a naturally high formation rate (Yang et al., 2009). We therefore looked for instances of bifurcating dendrites within our dataset. Evenly dividing bifurcations were defined as two daughter branches that differed in width by $\leq 15 \%$ (average width difference $4 \%$ ) to distinguish them from minor branches protruding from a main dendrite. We found that both high formation branches (HFBs) and low formation branches (LFBs) showed significant increases in spine formation $24 \mathrm{~h}$ after chessboard deprivation (HFBs: $t_{(6)}=3.33, p<0.02$; LFBs: $t_{(6)}=3.94, p<$ 0.01 , paired $t$ test), although the increase appeared larger for the HFBs (18.7\% increase above baseline vs $8.6 \%$ ) (Fig. 4). We compared the behavior of the HFBs and LFBs located at bifurcations with individual dendrites that we paired randomly. The HFBs in the random pairs again showed significant increases in spine formation with deprivation (HFB random: $t_{(6)}=4.05, p<0.01$; LFB random: $t_{(6)}=3.32, p<0.02$; paired $t$ tests), but the difference between HFB and LFB formation rates was smaller than with the natural bifurcating pairs ( $11.8 \%$ increase vs $9.1 \%$ increase). Taken across all time points following deprivation, spine formation was greater in the HFBs than the LFBs for the bifurcation pairs $\left(t_{(28)}=3.42, p<0.002\right.$, paired $t$ test) but was not different for the randomly assigned pairs $\left(t_{(26)}=1.3, p=0.2\right.$, paired $t$ test $)$. These findings suggest that, while baseline formation rate is predictive of a larger response to deprivation, a particular relationship exists between high and low formation pairs of dendrites at a bifurcation point. In concert with this finding, we found that the absolute rate of spine formation $24 \mathrm{~h}$ after deprivation was moderately well correlated with baseline spine rate for bifurcating pairs of dendrites $\left(r^{2}=0.45\right)$ but not at all for randomly paired dendrites $\left(r^{2}=0.002\right)$ (Fig. $\left.4 E, F\right)$.

Previous studies had not found structural plasticity in layer $2 / 3$ neurones in response to sensory deprivation (Hofer et al., 2009; Ma et al., 2016), but most studies in this area have looked at the apical dendrites rather than the basal dendrites. Apical and basal dendrites receive different afferent input on balance (Petreanu et al., 2009) as shown in Figure 5A. We therefore checked to see whether CWD had similar effects on the apical dendrites compared with the basal dendrites (Fig. 5B). We found that, $24 \mathrm{~h}$ after deprivation, formation and elimination rates were unaffected by CWD (Fig. 5C). Baseline formation rates were similar to that seen on basal dendrites $(4.7 \%$; Table 1$)$ and did not increase significantly following deprivation $\left(t_{(3)}=0.54, p=0.63\right.$, paired $t$ test). Similarly, elimination rates were similar to those of basal dendrites at $6.1 \%$, and while they appeared slightly higher follow- 
A

All whiskers deprived

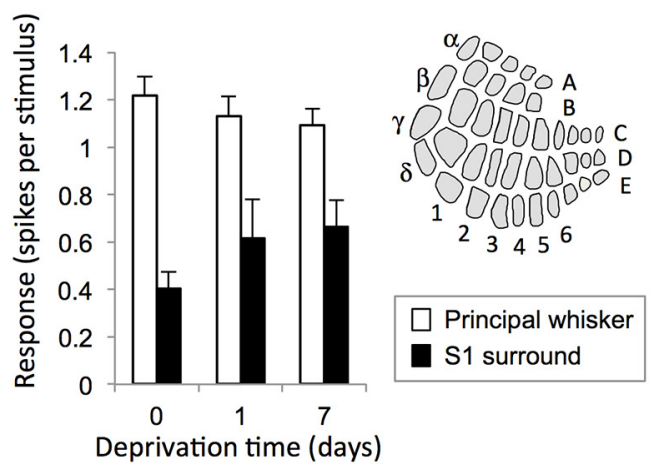

B

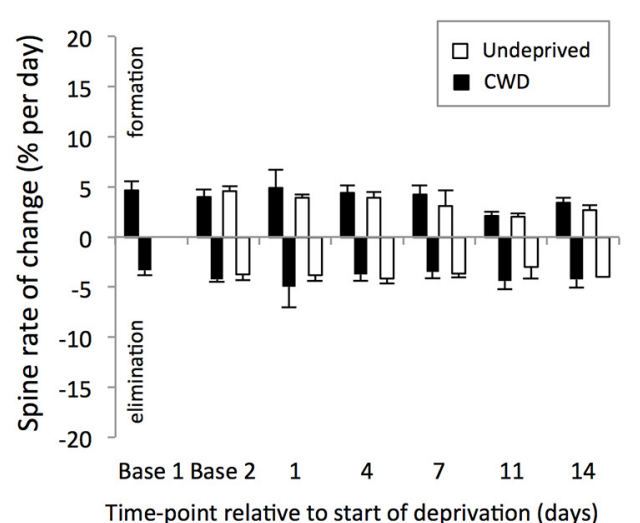

C

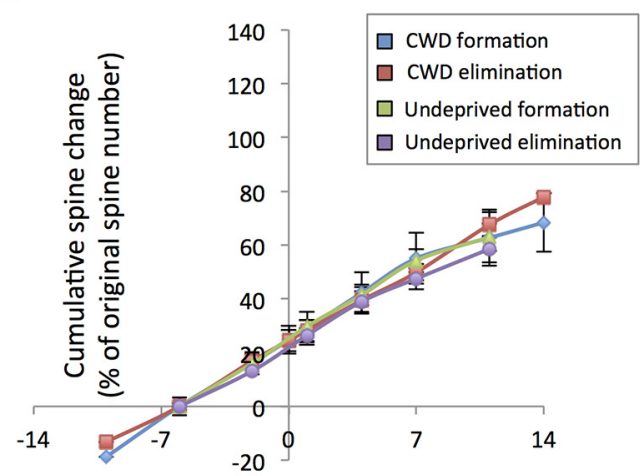

Time relative to the start of deprivation (days)
D

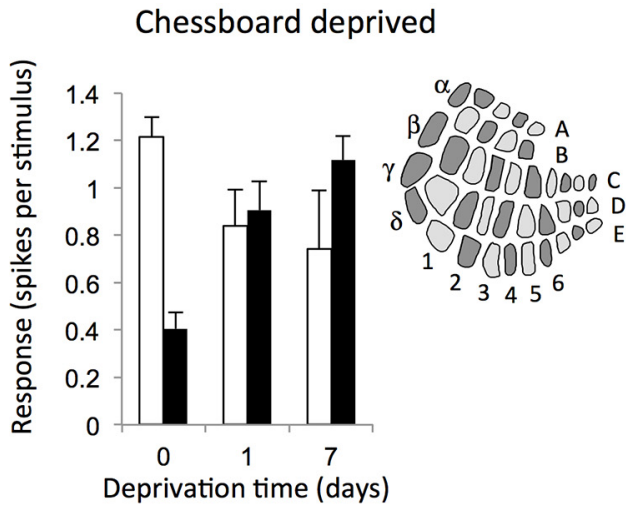

E

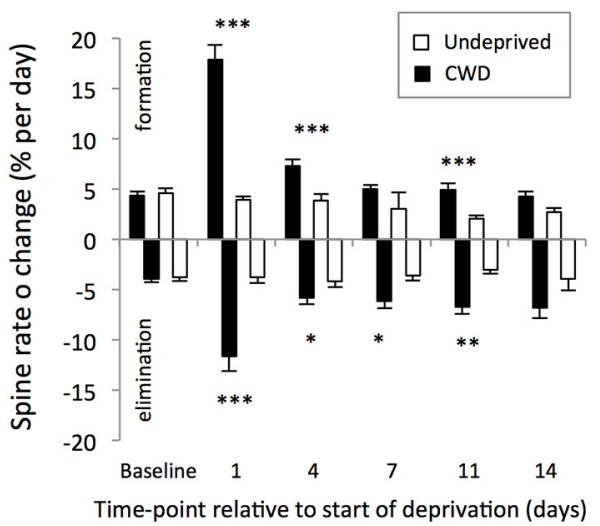

$\mathbf{F}$

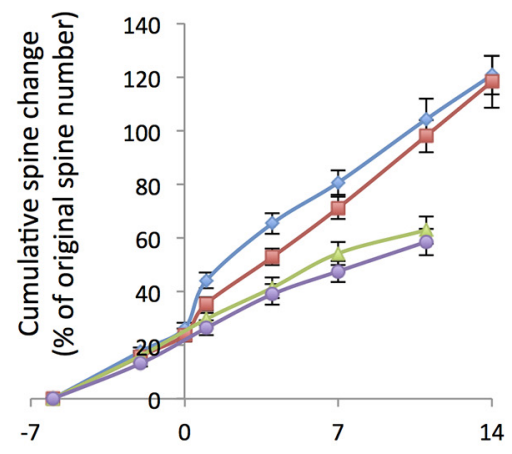

Time relative to the start of deprivation (days)

Figure 3. Effect of deprivation pattern on spine formation and elimination. $A$, AWD evenly deprives the barrel field of its principal whisker input and does not significantly alter principal whisker responses (white bars), nor the strongest (S1) spared surround whisker responses (black bars) after 1 or $7 \mathrm{~d}$ of deprivation. $\boldsymbol{B}$, Similarly, AWD does not affect spine formation (black bars) or elimination (black bars, plotted as negative values for clarity), which remain constant following deprivation compared with formation and elimination in undeprived animals (white bars). C, Therefore, AWD cumulative formation (blue line) and elimination curves (red line) entirely overlap with those for undeprived cases (see key). D, CWD results in alternate deprived and spared barrels in the cortex (diagram; spared barrels dark gray) and causes potentiation of spared whisker responses in deprived barrels (black bars) and principal whisker responses to depressed (white bars). $\boldsymbol{E}$, Similarly, CWD causes spine formation and elimination to increase significantly $1 \mathrm{~d}$ following deprivation and remain elevated for at least $11 \mathrm{~d}$ following deprivation compared with undeprived values. ${ }^{* * *} p<0.001 .{ }^{* *} p<0.01 .{ }^{*} p<0.05$. F, Consequently, cumulative spine formation is increased over $14 \mathrm{~d}$ to $\sim 90 \%$ of the originally present spines (blue line) compared with $\sim 40 \%$ in undeprived animals (green line). Cumulative spine elimination in CWD (red line) is similar to formation over $14 \mathrm{~d}$ and significantly higher than in undeprived animals (purple line).

ing deprivation at $8.3 \%$, were not significantly different from baseline measures $\left(t_{(3)}=1.5, p=0.22\right.$, paired $t$ test). Our results are therefore consistent with previous reports concerning apical dendrites, but additionally show that basal and apical dendrites behave differently under CWD.

\section{Spine formation and elimination in}

\section{$\alpha C a M K I I-T 286 A$ mutants}

To test whether the increase in spine formation we observe in chessboard-deprived WT mice is dependent on a cortical LTPlike process, we trimmed whiskers in a chessboard pattern in 
A

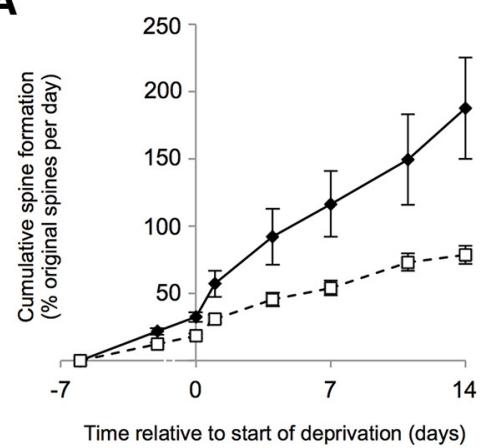

C

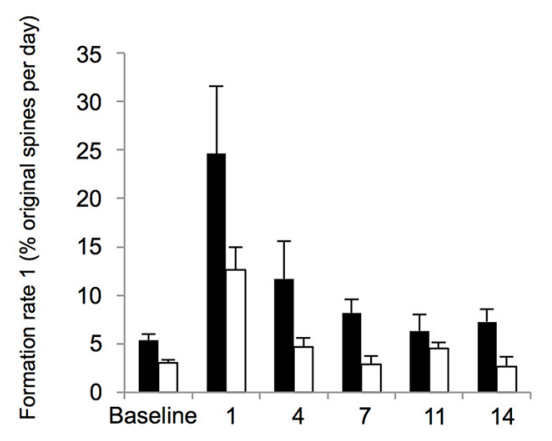

Time-point relative to start of deprivation (days)

E

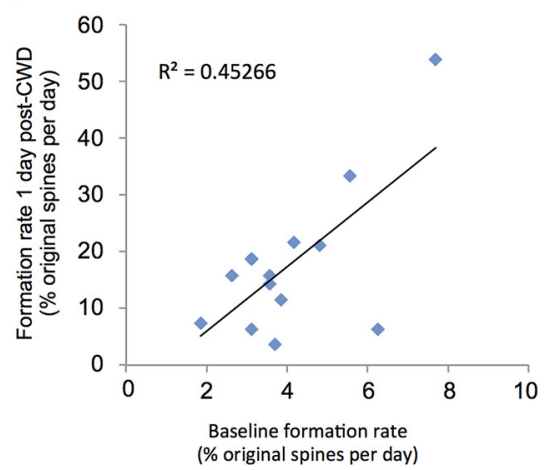

B

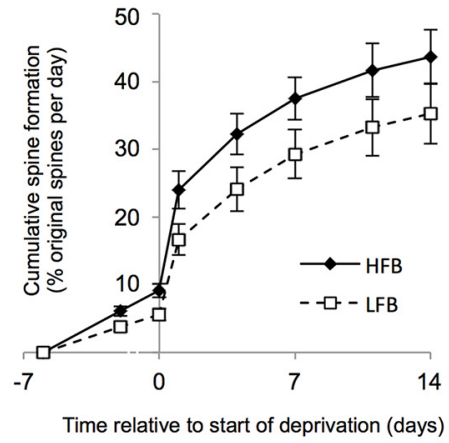

D

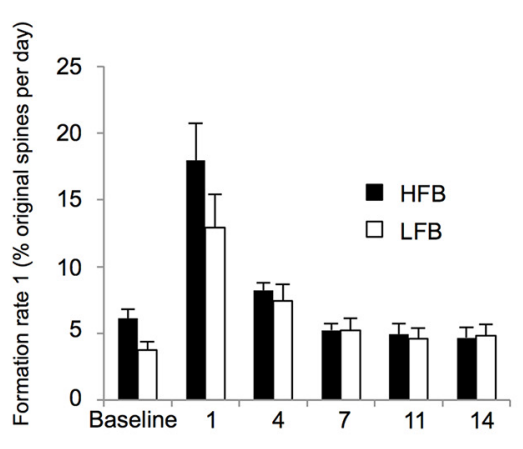

Time-point relative to start of deprivation (days)

$\mathbf{F}$

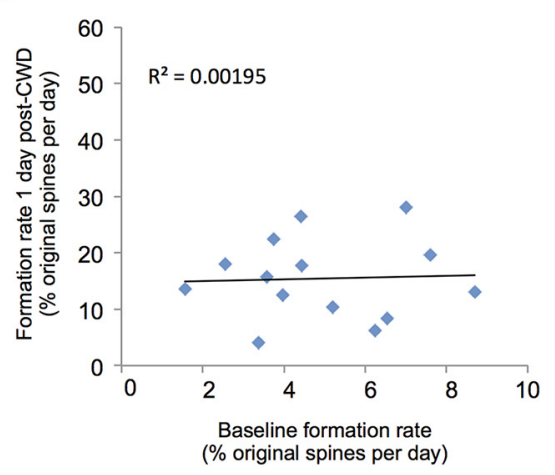

Figure 4. Effect of basal formation rate on chessboard pattern whisker deprivation induced formation rate in bifurcating dendrites and randomly paired singly assayed dendrites. $\boldsymbol{A}$, Bifurcating dendrites: the HFBs (solid lines, black diamonds) from the bifurcation pair are defined from their baseline formation rate and show a greater reaction to deprivation than LFBs (dashed lines, open squares). Plot represents the cumulative spine formation with time. $\boldsymbol{B}$, Random pairs: HFBs from randomly paired branches appear to show a greater reaction to deprivation, but this is not significantly different from the LFB random pair. $\boldsymbol{C}$, Bifurcating pairs: formation rate plotted in histogram format showing rates assayed per time point for HFBs (black bars) and LFBs (white bars). $\boldsymbol{D}$, Random pairs: formation rates for randomly paired dendrites. $\boldsymbol{E}$, Cross-correlation between basal formation and deprivation induced formation rates in bifurcation dendrite pairs. Basal formation is broadly predictive of deprivation induced formation $\left(r^{2}=\right.$ 0.45 ) and is highly significant (see Results). $\boldsymbol{F}$, Basal formation rate is not predictive of deprivation induced formation rate for randomly assigned pairs of dendrites $\left(r^{2}=0.00195\right)$.

$\alpha C a M K I I-T 286 A$ point mutants, which have an alanine substituted at the threonine 286 location; these animals lack CaMKII autophosphorylation (Miller and Kennedy, 1986; Giese et al., 1998 ) and both cortical LTP in the layer 4 to $2 / 3$ pathway (Hardingham et al., 2003) and cortical experience-dependent potentiation in layer 2/3 (Glazewski et al., 2000). We found that spine formation was unchanged $24 \mathrm{~h}$ following deprivation compared with their baseline predeprivation rates (baseline vs formation at day 1: $t_{(11)}=0.177, p<0.86$ ) (Fig. 6). Similarly, there was no difference between formation rates in deprived versus undeprived $\alpha$ CaMKII-T286A mice $\left(F_{(1,145)}=1.02, p=0.314\right)$.
Independent of deprivation, baseline formation and elimination rates were elevated in $\alpha$ CaMKII-T286A mice. Comparison of undeprived animals across all time points revealed formation rates of $3.8 \%$ for WTs and $4.9 \%$ for $\alpha C a M K I I-T 286 A$ mice, and these values were significantly different $\left(t_{(148)}=12.71, p<0.0005\right)$. Similarly, elimination rates were higher in $\alpha C a M K I I-T 286 A$ mice at an average of $4.1 \%$ in WTs versus $4.9 \%$ in $\alpha C a M K I I-$ T286A mice $\left(t_{(145)}=10.87, p<0.002\right)$. In these cases, as with others we studied, formation and elimination were closely matched over a timespan of several days, although the equilibrium could be temporarily interrupted by whisker deprivation. However, a striking exception to this rule was found with deprivation of the $\alpha C a M K I I-T 286 A$ mice. Chessboard deprivation increased spine elimination in a similar fashion to that seen in WTs (compare Fig. $3 E$ and Fig. $6 B$, negative values). Spine elimination increased to $15 \%, 24 \mathrm{~h}$ following deprivation compared with baseline $\left(t_{(11)}=3.99, p<0.002\right.$; paired $t$ test), although no other time point was significantly different from undeprived cases. In the absence of spine formation, this transient period of spine elimination produced a net loss of spines that were not replaced over the period of observation.

We also compared formation and elimination rates across WT and $\alpha$ CaMKIIT286A mice following chessboard deprivation. We found a significant interaction between time and genotype $\left(F_{(4,122)}=\right.$ 9.06, $p<0.0001)$ due to a higher formation rate in the WTs at 1 and $4 \mathrm{~d}$ following deprivation (compare Fig. $3 E$ and Fig. $6 B$ ) $\left(F_{(1,29)}=26.0, p<0.001\right.$ for $1 \mathrm{~d}$ and $F_{(1,28)}$ $=6.54, p<0.02$ at $4 \mathrm{~d})$. However, ANOVA showed that elimination rates were not different between the two genotypes $\left(F_{(1,26)}=0.07, p=0.78\right)$, even though elimination appeared to last a shorter period after deprivation in $\alpha$ CaMKIIT286A mice. These results show that experience-dependent formation of new spines is dependent on CaMKII autophosphorylation, whereas elimination is not.

\section{Spine persistence, spine head size, and spine morphology} in WTs

\section{Spine persistence}

The new spines that appear on the first day of whisker deprivation in chessboard-deprived WT mice may either disappear quite quickly or last for some period of time; and in the latter case, they may be capable of forming the substrate for experiencedependent potentiation. To investigate the persistence of new spines, we plotted the rate of spine loss for newly formed spines 
(i.e., those spines not present in the baseline time period, but which first appeared $24 \mathrm{~h}$ after whisker trimming) (Fig. 7A).

Spine lifetimes for new spines were biphasically distributed, with transient spines (observed for just a single time point) and new persistent spines (NPSs, lasting at least $13 \mathrm{~d}$ ) dominating the distribution. In undeprived animals, $57 \%$ of new spines were transient and just 29\% persistent. This pattern was reversed in CWD mice where $29 \%$ were transient and $45 \%$ persistent. Consequently, the average lifetime of a new spine increased significantly following whisker deprivation $\left(\chi_{(1)}^{2}=12.7, p<0.0005, n=188\right.$, Wilcoxon test). When coupled with the increased production of spines $1 \mathrm{~d}$ following deprivation, this led to a substantial increase in the proportion of NPSs. Over the observation period, $\sim 8 \%$ of new spines were persistent in chessboard-deprived animals compared with $<1 \%$ in undeprived animals (Fig. 7A).

Chessboard whisker deprivation creates a mosaic pattern of barrels in the cortex where a barrel that has lost its principal whisker input due to whisker trimming sits next to several barrels with intact principal whisker input (Fig. 1D). Electrophysiological measurements of evoked whisker responses showed that potentiation of responses to spared whisker stimulation occurs in deprived barrels and spared barrels (Fig. 2C,D). In other words, the spared whisker components of surround receptive fields are potentiated in general by CWD. In concert with this finding, we observed that the (increased) lifetime of newly formed spines following CWD was identical in the deprived and spared barrels $\left(\chi_{(1)}^{2}=0.74, p=0.38, n=\right.$ 73, Wilcoxon test).

A substantial component of the spines present on the dendrites following deprivation was present in the baseline from the start of observations (Fig. 7B). These spines are likely to code for the preexisting receptive field properties of the neurones, which tend to be dominated by the principal whisker. Given that the principal whisker response decreases following chessboard deprivation, again in deprived and spared barrels (Fig. 2) (Wallace and Fox, 1999b), we looked at how spine lifetime was affected by deprivation in this subpopulation of spines. We found that whisker deprivation increased the rate of spine loss from the first day of deprivation (Fig. $7 B$ ). In undeprived animals, the proportion of surviving spines was asymptotic at $\sim 65 \%$ of the original number after $21 \mathrm{~d}$ of observation, suggesting that $\sim 65 \%$ percent of spines were stable. In chessboard-deprived mice, the proportion of surviving spines dropped to $48 \%$ over the same observation

D

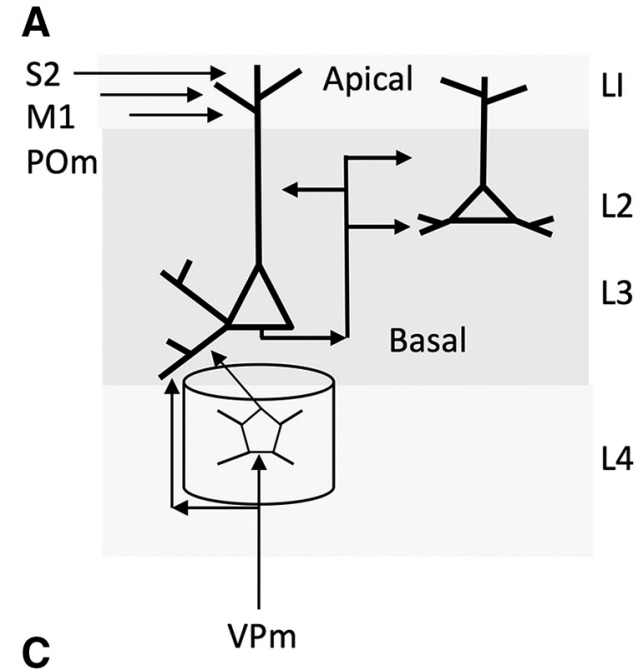

B

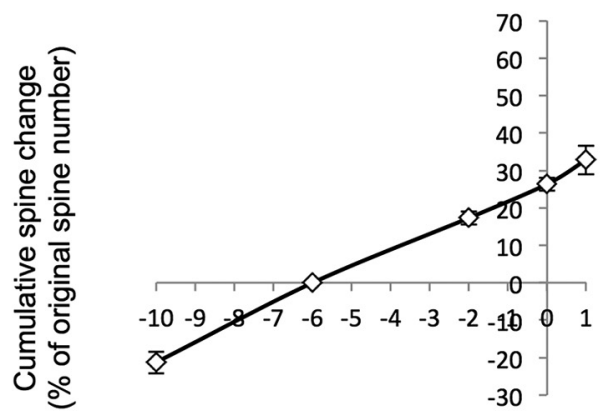

Time relative to the start of deprivation (days)

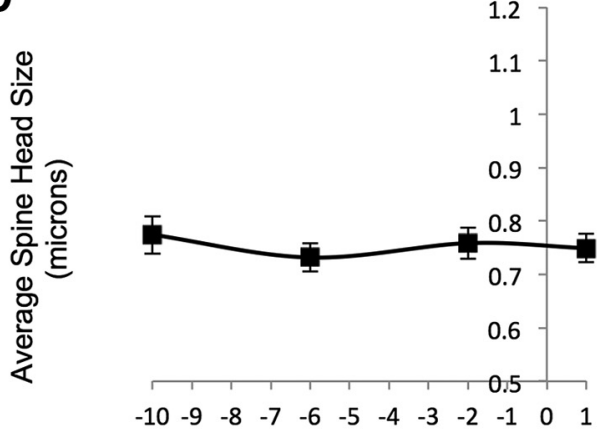

Time relative to the start of deprivation (days)

Figure 5. Lack of effect of CWD on measures of synaptic plasticity on apical dendrites in barrel cortex. A, Diagram of barrel cortex showing the inputs to apical dendrites in layer I (LI) and the different inputs to basal dendrites in layers 2 (L2) and layer 3 (L3). Inputs to apical dendrites arise from other cortical areas, such as secondary somatosensory cortex (S2) and primary motor cortex (M1) as well as the medial part of the posterior thalamic nucleus (POm). Basal input arises from layer 4 cells and other layer $2 / 3$ cells as well as some direct VPm input onto layer 3 cells. Bi, Low-power image of apical dendrites in L1. Bii-Biv, Descending sequence of images from 30 to $180 \mu \mathrm{m}$ below the dura. Biv, Scale bar, $30 \mu \mathrm{m}$. C, The cumulative spine formation rate is shown for baseline time points and for $1 \mathrm{~d}(24 \mathrm{~h})$ after chessboard whisker deprivation. The plot does not show an increase in slope $1 \mathrm{~d}$ after deprivation that would be characteristic of increased spine formation and is seen with CWD for basal dendrites (compare with Figs. $3 F$ and $4 A, B$ ). $D$, The spine sizes of the stable (AP) population of spines were calculated for each time point and show no change postdeprivation (compare with Fig. $9 B$ for basal dendrites).

period, implying an increased loss of at least $17 \%$ due to deprivation. Consequently, spine lifetime decreased significantly in chessboard-deprived animals for spines already present at the first observation point $\left(\chi_{(1)}^{2}=10.9, p<0.001, n=472\right.$, Wilcoxon test); and once again, this value was not significantly different between spared and deprived barrels $\left(\chi_{(1)}^{2}=0.24\right.$, $p=0.62, n=310$, Wilcoxon test). 
A

\section{aCaMKII-T286A (Chessboard)}

\section{B}
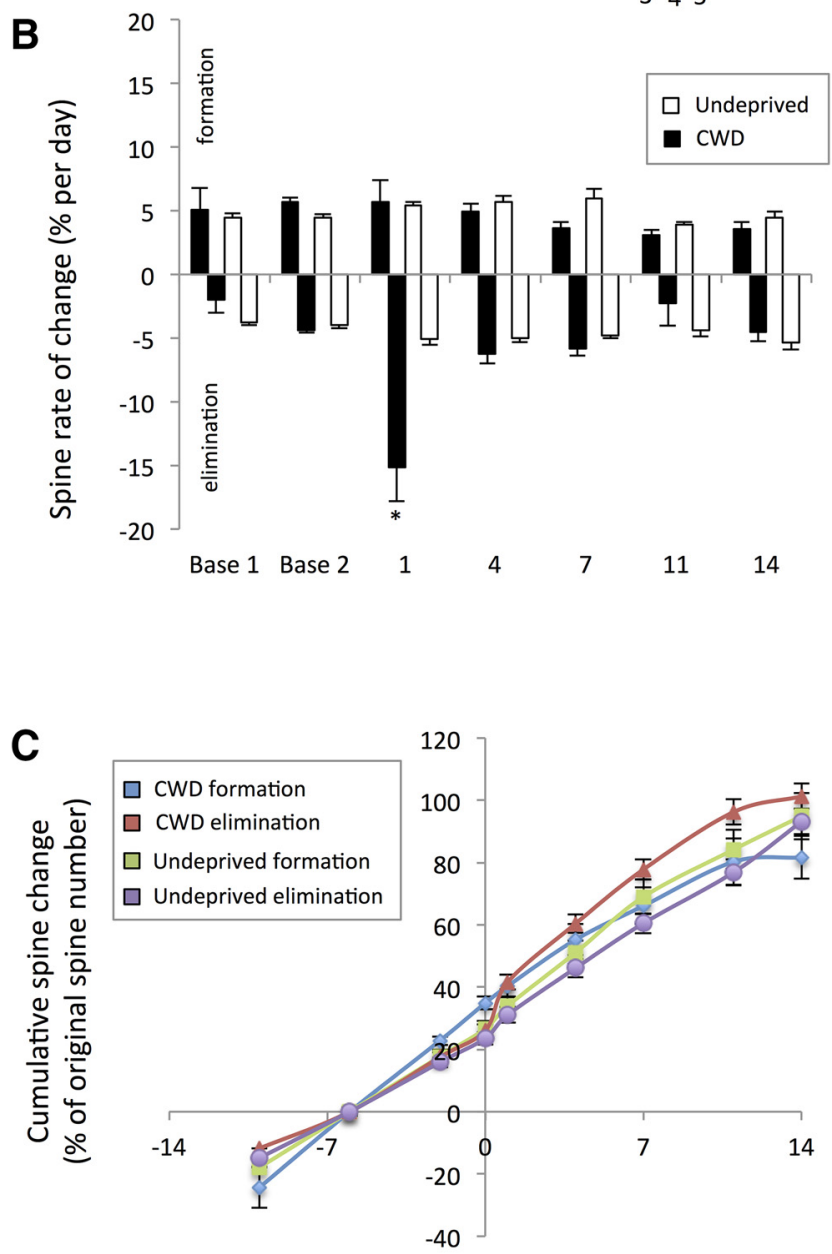

Time relative to the start of deprivation (days)

Figure 6. Lack of effect of CWD on spine formation in $\alpha$ CaMKII-T286A homozygous mice. $A$, Diagrammatic representation of the chessboard-deprived pattern. $B$, CWD (black bars) does not cause an increase in spine formation (positive values) above baseline (white bars) following deprivation. However, spine elimination (plotted as negative values for clarity) is increased on the first day following whisker deprivation (black bars) relative to undeprived $\alpha$ CaMKII-T286A (white bars). ${ }^{*} p<0.05$. C, Cumulative formation curves overlap for deprived (blue line) and undeprived (green line) $\alpha$ CaMKII-T286A mice and are not different, whereas cumulative spine elimination (red line) increases $1 \mathrm{~d}$ after deprivation but returns to basal rates thereafter.

Spine head size for new and eliminated spines

The lifetime of a spine is normally closely related to the size of the spine head, with larger spines exhibiting longer lifetimes than smaller spines (Yasumatsu et al., 2008). We therefore looked at the distribution of spine head sizes of spines newly formed $24 \mathrm{~h}$ after deprivation that persisted for the duration of the CWD period and compared it with the distribution for spines that were present before deprivation and persisted over the whole observation period. We found that the distribution of spine head sizes for NPSs after $24 \mathrm{~h}$ (Fig. 8A) was not significantly different from that for the stable spines that were present throughout the observation period (always present spines [APSs]; $F_{(1,173)}=3.13, p=0.07$ ). However, NPS heads were significantly larger than those of transient spines (present for a single time period) $\left(F_{(1,86)}=5.76, p<\right.$ $0.02)$. NPSs were also larger than newly formed spines that were subsequently lost over the next $13 \mathrm{~d}$ (Fig. 8C,D). A two-way ANOVA showed an effect of head size on persistence of newly formed spines at $24 \mathrm{~h}\left(F_{(1,185)}=3.61, p<0.002\right)$, with the difference also apparent at 4,7 , and $11 \mathrm{~d}$ following deprivation. These findings suggest that NPSs rapidly acquire the same spine head size as the stable population of AP spines after just $24 \mathrm{~h}$, which prompted us to study spine head size at a briefer $12 \mathrm{~h}$ time point. We found that spine head sizes for NPSs at $12 \mathrm{~h}\left(\mathrm{NPS}_{12}\right)$ were smaller than those at $24 \mathrm{~h}\left(\mathrm{NPS}_{24}\right)$ and not different from those of transient spines $\left(F_{(1,99)}=5.05, p<0.01\right)$. These results suggest that newly formed spines become established somewhere between 12 and $24 \mathrm{~h}$ following deprivation (Fig. 8C,D).

We also looked at the sizes of spines that become eliminated following whisker deprivation. During the deprivation period, spines that were lost had significantly smaller spine heads than those of the baseline AP population of spines $\left(F_{(1,296)}=18.8, p<\right.$ 0.0001) (Fig. 8B).

\section{Induced changes in spine head size for stable spines}

We were interested to see whether CWD caused a general increase in spine head size, as this might provide a structural substrate for the potentiation of spared whisker responses in addition to the increased numbers of NPSs. When the overall spine population was considered, which included stable and transient populations of spines, we found little overall change in spine size and no statistically significant effects (Fig. 9A, C,E). However, spine sizes vary from one time point to another, due partly to spontaneous spine fluctuations (Yasumatsu et al., 2008) and due partly to the variety of spine lifetimes (and therefore spine sizes) present in any given sample (Fig. 8). The AP subpopulation of spines, while still showing spontaneous spine fluctuations, were at least free of the variability in spine size due to transient and intermediate spine lifetimes. We therefore tested whether there was an effect of CWD on the AP population of spines. We found that spines in deprived and spared barrels increased in spine head size following deprivation (Fig. $9 B, D$ ). Within the general population of AP spines, individual spines increased and others decreased in size, but overall the population increased in size (Fig. 9D).

There was a clear relationship between the size of the spines at baseline and its direction of size change following deprivation (Fig. 9F). The small spines tended to show increased head sizes, whereas the larger spines showed decreased head sizes. This effectively provided an apparent homeostatic reaction to the CWD-induced enlargement seen in the stable spine population. The increase in the population spine head size was therefore due to many small spines increasing and only being partly compensated by fewer large spines decreasing in head-size.

The change in spine size was relatively small (on average $10 \%$ ). Nevertheless, the AP spines represent $\sim 65 \%$ of the total spine population at any one time (dependent on age), and the general effect may therefore be physiologically significant. We found no difference in spine size between the control period baseline time points $\left(t_{(147)}=1.13, p=0.26\right)$, but all the baseline time points differed from all the postdeprivation time points (e.g., at $1 \mathrm{~d}$ postdeprivation, $t_{(147)}=4.05, p<0.0001$, matched-pair $t$ test; for full statistics, see Fig. 9 legend).

We also looked to see whether apical dendrites also showed increases in the size of the stable spine population following CWD. We found that, unlike basal dendrites, the stable spine 
A

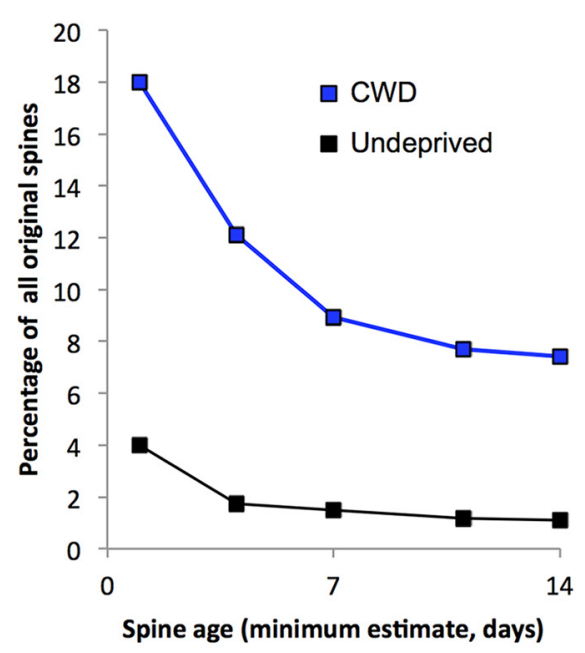

B Initially present spine elimination

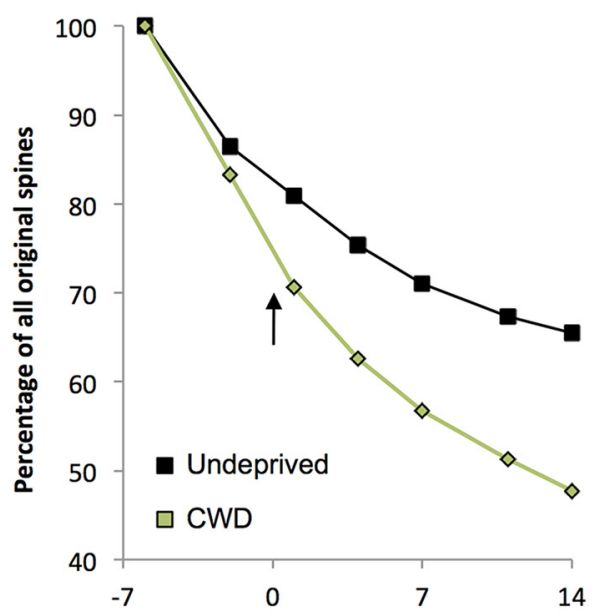

Time relative to the start of deprivation (days)

Figure 7. Effect of chessboard whisker deprivation on lifetime of newly formed and already present spines. A, Newly formed spines in CWD WT mice (blue line) comprise $18 \%$ of initially present spines $1 \mathrm{~d}$ following deprivation. The new spine count decays with time to asymptote at $\sim 8 \%$ by $14 \mathrm{~d}$ of deprivation. New spines in undeprived WTs only comprise $4 \%$ of the total on any given day and decay to $\sim 1 \%$ over the same time period (black line). $\boldsymbol{B}$, Spines already present at the first observation time point naturally decay over time in undeprived animals (black line) to asymptote at $\sim 65 \%$ of the population after $20 \mathrm{~d}$. CWD (onset shown by arrow) increases the rate of decay (green line) by $\sim 18 \%$ over the same period. Spines summed across all cases in each group.

population on the apical dendrites showed no change in population spine size $24 \mathrm{~h}$ following deprivation $\left(t_{(97)}=0.76, p=0.44\right.$, matched-pair $t$ test) (Fig. 5D). It was also apparent that the average size of the apical dendrite spine heads was in general smaller than those of basal dendrites when comparing baseline measures with undeprived controls over a similar period of time $\left(F_{(1,589)}=\right.$ $11.8, p<0.001)$.

We also tested to see whether the AP population of spines changed size in the AWD mice. In contrast to the effect of CWD, we found that AWD produced a small decrease in average spine size (Fig. 9B). Overall, AWD reduced AP spine head size to 94\% of control values over the deprivation period, and this was a significant effect $\left(F_{(1,1285)}=4.03, p<0.0002\right)$. The effect was clearer from $7 \mathrm{~d}$ onward, and AP spine head sizes averaged $90 \%$ of control values after $14 \mathrm{~d}$ of AWD $\left(_{(137)}=3.43, p<0.0005\right.$, matched-pair $t$ test).

\section{Spine morphology}

We classified spines into one of four types, mushroom spines, thin spines, stubby spines, and filopodia (see Materials and Methods), using previously published criteria (Grutzendler et al., 2002; Oray et al., 2006; Rodriguez et al., 2008). In the general population of all spines, we found that most spines were thin $(61 \%)$, many were mushroom (16\%), and a few were filopodia (9\%) (Table 2). The rest were classified as apparently stubby spines, where the neck was short and appeared to be of similar size to the head (14\%).

We found that the NPS population differed in morphology from the general population, even after $14 \mathrm{~d}$ of CWD, comprising fewer mushroom spines (5\% vs $16 \%$ ) and more stubby spines and filopodia $\left(\chi_{(9)}^{2}=63, p<0.001\right.$; Table 2$)$. This suggests that it takes longer than $14 \mathrm{~d}$ for most of the very largest spine types to become established from genesis. We also looked at the stable population of AP spines and found that they progressively lost mushroom spines over the $14 \mathrm{~d}$ postdeprivation period from $16 \%$ to $2 \%$ by day $14\left(\chi_{(9)}^{2}=40, p<0.001\right.$; Table 2$)$, being replaced mostly with thin and stubby spine types. If one assumes that the principal whisker probably transmits via mushroom spines in its principal barrel, this finding is in keeping with the physiological data showing that principal whisker responses decrease with chessboard deprivation. It is also in keeping with the general finding that larger spines tend to decrease and smaller spines increase in size with deprivation (Fig. $9 F$ ). On average, a small increase in spine head size in the AP population occurs with CWD (Fig. $9 B, D$ ) accompanied by a reduced number of mushroom spines.

\section{Spine persistence, spine head size, and spine morphology in $\alpha C a M K I I-T 286 A$ mutants}

Spine persistence

Given the relationship between spine lifetime and spine size, we tested whether the higher baseline formation and elimination rates present in $\alpha$ CaMKII-T286A mice resulted in shorter spine lifetimes in general and whether the size of the spines was subsequently different. Indeed, spine lifetimes were found to be briefer in $\alpha C a M K I I-T 286 A$ mutants compared with WTs (Fig. 10A). A two-way ANOVA showed an effect of deprivation and genotype on spine lifetime but no interaction between the two $\left(F_{(3,1059)}=\right.$ 7.65, $p<0.0001)$. In undeprived $\alpha$ CaMKII-T286A mutants, spines that were already present from the first observation point were eliminated at a faster rate than in WTs (Fig. $10 A ; \chi_{(1)}^{2}=7.0$, $p<0.01, n=511$, Wilcoxon test) falling to $50 \%$ of the original number over $20 \mathrm{~d}$. This is consistent with the observation that baseline spine formation and elimination is higher in $\alpha C a M K I I-$ T286A animals than in WTs. The rate of spine loss was increased further by deprivation (Fig. $10 A ; \chi_{(1)}^{2}=8.8, p<0.003, n=588$, Wilcoxon test) and resulted in just $38 \%$ of spines persisting for $20 \mathrm{~d}$. Neither decay curves for surviving spines in deprived nor undeprived animals reached an asymptote over the period of observation (Fig. 10A). Spine loss was $\sim 12 \%$ greater in deprived $\alpha C a M K I I-T 286 A$ mice than in undeprived control cases after $14 \mathrm{~d}$ of CWD. These observations are consistent with the electrophysiological evidence, which shows that CWD causes depression of deprived 
A Spine head size distribution: New
persistent and always present spines

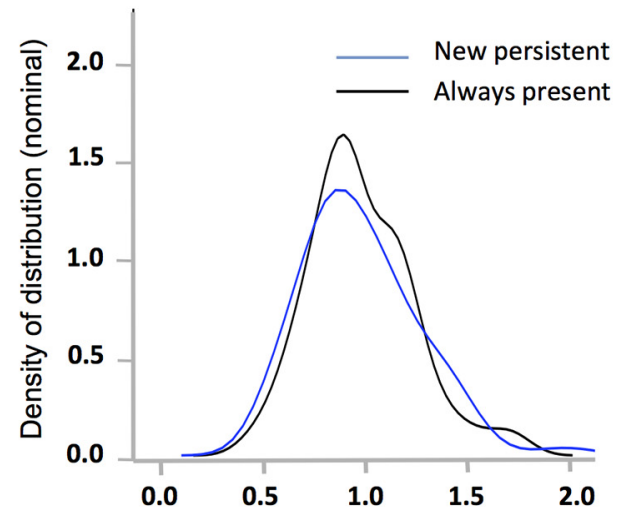

Spine head size (microns)

C

Time course of spine head size changes
B

\section{Spine head size distribution: lost and always present spines}

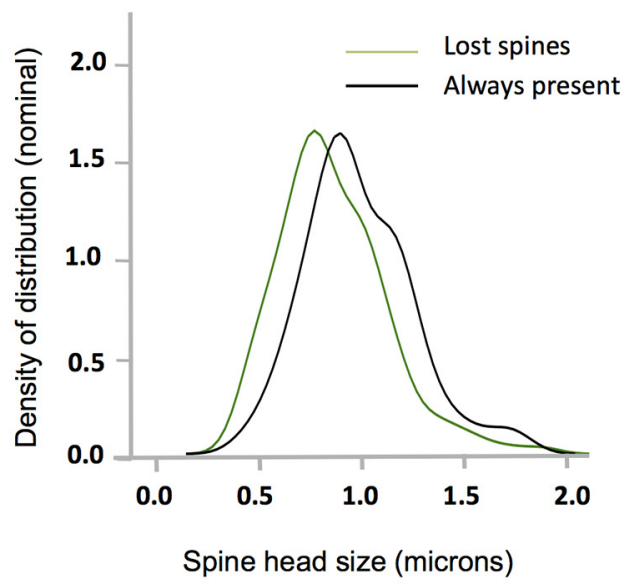

D

\section{Relationship between spine head size and spine persistence}
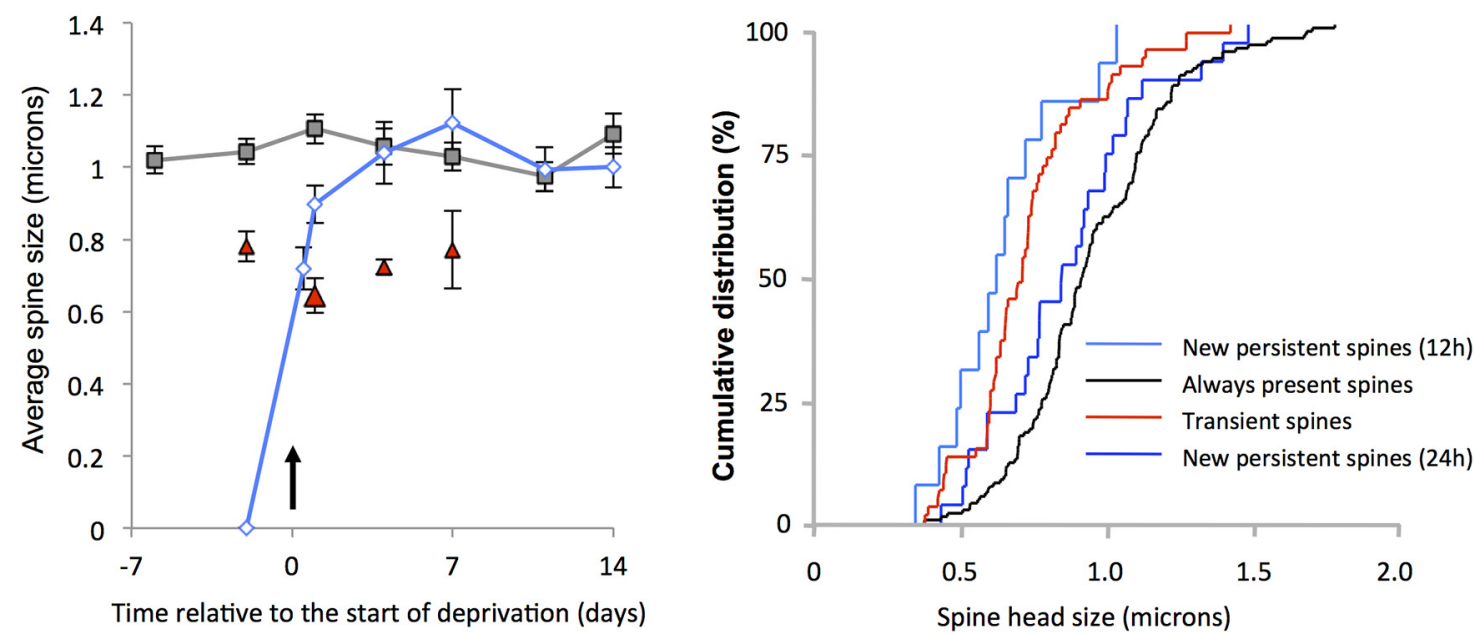

Figure 8. Relationship between spine size and lifetime for eliminated, transient, and NPSs in WTs. A, New spines formed after chessboard deprivation that persist (blue line) have the same spine head size distribution $24 \mathrm{~h}$ after deprivation as the stable spine population (black line). $\boldsymbol{B}$, Spines that are eliminated one time point following observation of their presence (green line) are smaller than the stable spine population (black line). C, The average spine head size of the stable spine population for undeprived WTs is plotted over a 3 week period (gray line, mean and SEM). Transient spines (present for a single time point) have smaller average spine head sizes (red triangles). Average head size of NPSs (blue line) increases rapidly between 12 and $24 \mathrm{~h}$ of chessboard whisker deprivation to exceed transient spine head sizes at $24 \mathrm{~h}$ and is indistinguishable from the stable spine sizes after $4 \mathrm{~d}$. D. Cumulative distribution functions for the spine head sizes of transient (red), new persistent at $12 \mathrm{~h}$ (light blue), new persistent at $24 \mathrm{~h}$ (dark blue), and stable spines (black) shown in $\mathrm{C}$.

whisker responses in $\alpha$ CaMKII-T286A mice but no potentiation of spared whisker responses (Hardingham et al., 2003).

Spine lifetime for new spines produced $24 \mathrm{~h}$ following deprivation were similar to those of WTs. However, the number of new spines formed after deprivation were no greater than at any other time point (Fig. 10B), which meant that, after $14 \mathrm{~d}$ of deprivation, the number of spines formed $24 \mathrm{~h}$ after deprivation was $1.3 \%$ of the total and not significantly different from the number expected in undeprived $\alpha$ CaMKII-T286A mutants of $0.8 \%$ (Fig. 10B).

Spine head size for new and eliminated spines

We compared NPSs formed on the first day following deprivation with spines that were stable and always present (AP) throughout the entire observation period in undeprived animals. We found that, just as with WTs, NPSs had the same size spines heads as the AP population in $\alpha$ CaMKII-T286A mice (Fig. 10D). However, spine heads of all types were generally smaller than in WTs. A two-way ANOVA showed an effect of genotype but not of spine type (AP vs NP) across WTs and $\alpha$ CaMKII-T286A mutants $\left(F_{(3,394)}=4.88, p<0.003\right)$. Post hoc test showed that this was because persistent spine heads were significantly smaller in $\alpha$ CaMKII-T286A mutants than in WTs $\left(t_{(393)}=3.29, p<0.002\right)$. This conclusion was strengthened when we further tested whether spine head sizes were different in undeprived WTs and $\alpha C a M K I I-T 286 A$ mutants (Fig. $10 E, F$ ) and found they were $\left(t_{(1281)}=6.89, p<0.0001\right)$

We also compared the size of transient spines with the persistent spine population and found once again that, as with WTs, transient spines were significantly smaller than persis- 
A

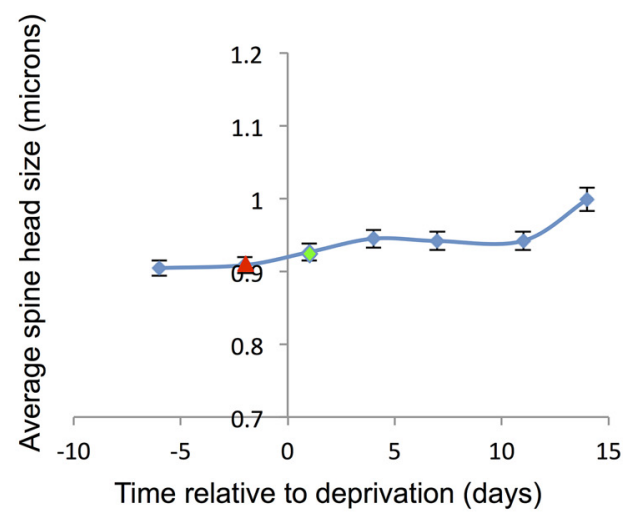

C

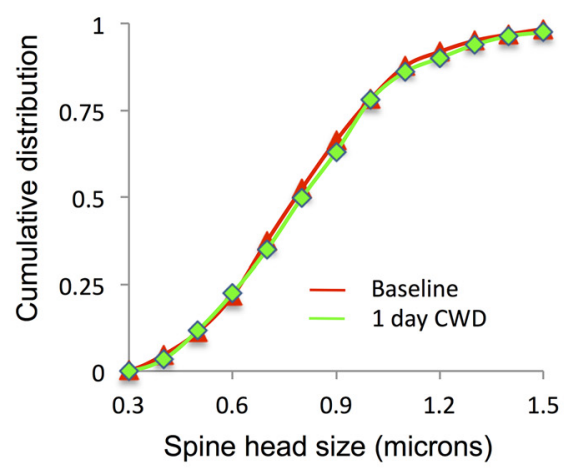

$\mathbf{E}$

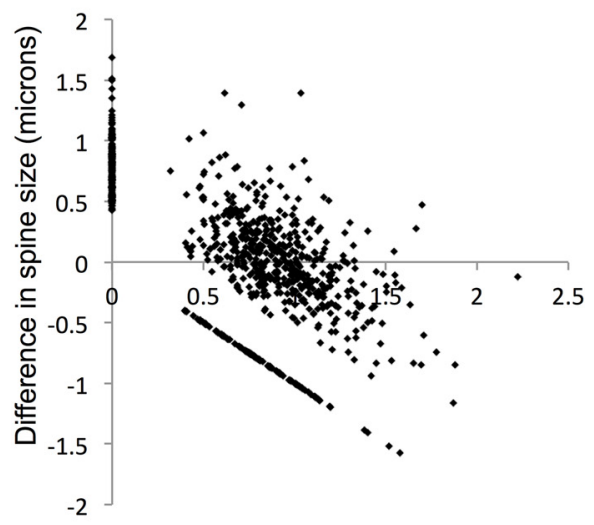

Baseline spine head size (microns)
B

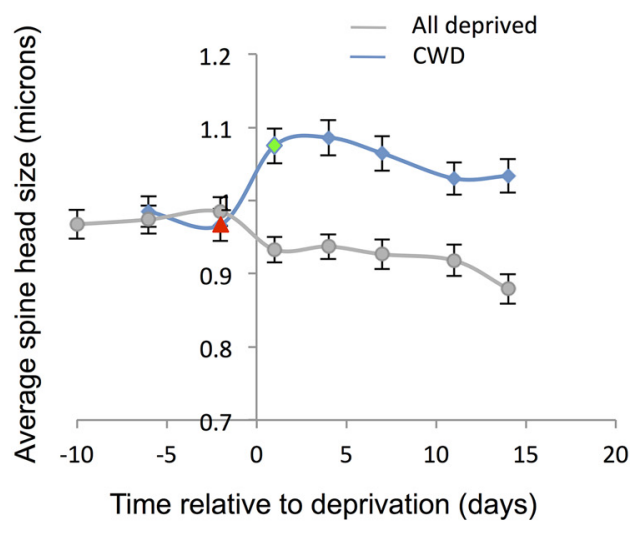

D

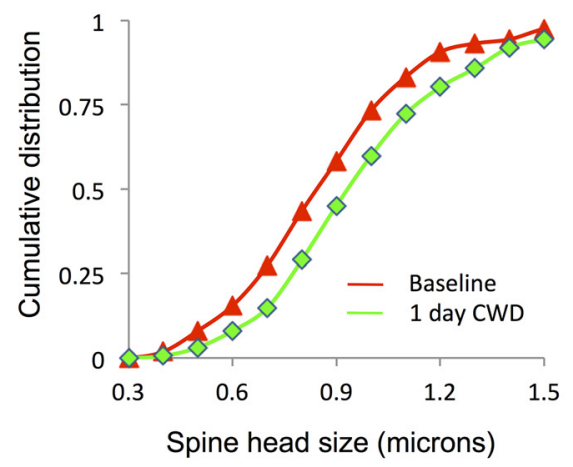

$\mathbf{F}$

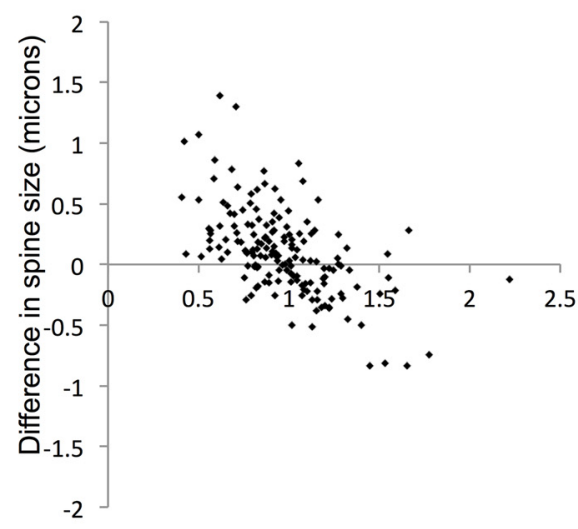

Baseline spine head size (microns)

Figure 9. The effect of deprivation pattern on spine size of the stable spine population in WTs. A, The overall spine head size in the general population of all spines does not change with CWD. $\boldsymbol{B}$, However, the average spine head size does increase in the population of APSs with CWD (blue line), though not AWD (gray line). C, Cumulative distribution functions for the general population of all spines before (red) and after deprivation (green) are similar (red and green lines correspond to red and green time points in $\boldsymbol{A}$ ). $\boldsymbol{D}$, However, the cumulative distribution function for the stable spine population shifts right (larger values) from baseline (red) after CWD (green). Log-transformed spine size distributions for each time point were compared using matched-pair $t$ tests. Baseline time points were not different $\left(t_{(147)}=1.13, p=0.26\right)$, whereas baseline and day $1,4,7,11$, and 14 were different $\left(t_{(147)}=4.0, p<0.0001 ; t_{(147)}=4.44, p<0.0001 ; t_{(147)}=3.63, p<0.0004 ; t_{(147)}\right.$ $=2.50, p<0.013 ; t_{(147)}=2.3, p<0.022$, respectively). $\boldsymbol{E}$, The change in spine head size is related to the original size of the spines and is shown for the general population of spines in $\boldsymbol{E}$ and for the stable spines only in $\boldsymbol{F}$. Newly formed spines appear on the $y$ axis, and eliminated spines appear along $x=-y$. $\boldsymbol{F}$, Spine larger than $\sim 1 \mu \mathrm{m}$ tend to decrease in size, whereas those smaller than $1 \mu \mathrm{m}$ increase in size.

tent spines $\left(\chi^{2}=68.75, p<0.0001\right)$. These findings suggest that spine head size is an important determinant of spine stability in $\alpha$ CaMKII-T286A mutants just as in WTs, but that the critical size for stability is smaller in $\alpha$ CaMKII-T286A mutants.
Changes in spine head size for initially present spines

As described above, we found that, in WTs, the AP population of spines showed a small but significant increase in spine head size following deprivation. We found no comparable change in $\alpha C a M K I I-T 286 A$ mice, however (Fig. $11 A, B$ ); and the average 
Table 2. Percentages of basal dendritic spines in different morphological classes by genotype and spine lifetime classification ${ }^{a}$

\begin{tabular}{lclll}
\hline & Filopodia & Stubby & Thin & Mushroom \\
\hline WT (all spines) undeprived & 9 & 14 & 61 & 16 \\
AP spines (day 1) & 14 & 14 & 63 & 9 \\
AP spines (day 14) & 25 & 17 & 56 & 2 \\
N spines (day 1) & 26 & 35 & 31 & 8 \\
NP spines (day 14) & 28 & 13 & 54 & 5 \\
$\alpha$ CaMKII-T286A (all spines) undeprived & 2 & 4 & 87 & 7 \\
\hline
\end{tabular}

${ }^{a} \mathrm{AP}$, Always persistent spines, either viewed 1 or $14 \mathrm{~d}$ after $\mathrm{CWD} ; \mathrm{N}$, new spines produced on the first day of deprivation (day 1) and day 14. $\alpha$ CaMKII-T286A mice in the last row and WTs in the first row were undeprived, and the general population were classified independent of spine lifetime.

spine sizes for the population of AP spines were not different from any pair of baseline to postdeprivation comparisons (e.g., baseline to day $1, t_{(86)}=1.04, p=0.299$; Fig. 11). However, just as with the WT cases, individual spines in the $\alpha$ CaMKII-T286A mice showed increases and decreases in spine size from one time point to another (Fig. 11C). Consistent with spine fluctuation analysis, the smaller spines tended to increase in size and the larger spines decrease in size (Fig. 11D), but overall the spine head size distribution remained unchanged by deprivation. The effect of fluctuations is therefore not dependent on CaMKII autophosphorylation. However, because the spontaneous increases in spine size within the population are small compared with those in WTs (due to a lack of potentiation in these animals), the fluctuation range is also smaller and the spine population settles to a smaller average spine head size (Fig. $11 A, C, D)$.

\section{Spine morphology}

The distribution of spine types found in undeprived $\alpha$ CaMKIIT286A mice was different from that seen in WTs, with fewer mushroom spines $(6.5 \%)$ and more thin spines (87\%) (Table 2; $\left.\chi_{(3)}^{2}=64.5, p<0.0001\right)$. This result is in keeping with the general finding that spine head sizes were smaller in $\alpha C a M K I I-T 286 A$ mice than in WTs, which may be related to their lack of LTP and may thereby give rise to their higher basal levels of spine elimination.

\section{Discussion}

This study shows that layer $2 / 3$ neurones do undergo structural plasticity in the barrel cortex, but (1) only under conditions that produce functional plasticity of receptive field structure (CWD not AWD) and (2) only on the basal and not the apical dendrites. Why does CWD cause functional and structural plasticity while AWD does not? CWD alters the natural timing of activity in columnar and trans-columnar circuits driven by spared and deprived whiskers and therefore creates the conditions for spiketiming dependent potentiation and depression (Wallace and Fox, 1999a; Celikel et al., 2004). The spared whiskers can also provide activity for non-spike-timing forms of LTP in barrel cortex (Gambino and Holtmaat, 2012). Neither of these contingencies are created by AWD, which leads to a uniform decrease in activity levels and consequently little opportunity for Hebbian forms of plasticity. At the ages studied here, neither does AWD cause homeostatic plasticity (compare Fig. 2B with Glazewski et al., 2017). In common with the visual cortex (Ranson et al., 2012), barrel cortex appears to exhibit homeostatic plasticity in young rather than adult animals.

Our findings may help to explain earlier studies that did not observe structural plasticity in layer $2 / 3$ cortical neurones. Studies in barrel cortex where all the whiskers were deprived uniformly also reported a lack of rapid structural plasticity in layer $2 / 3$ neurones (Zuo et al., 2005; Ma et al., 2016). Studies in visual cortex, where activity was uniformly decreased in the monocular zone by contralateral eye enucleation, also found a lack of structural plasticity in layer 2/3 (Barnes et al., 2015). One study in binocular visual cortex did use monocular deprivation, however, which would be expected to create activity contrasts between ipsilateral and contralateral eye inputs. In this case, no structural plasticity was found on the layer 2/3 neurones (Hofer et al., 2009), possibly because the apical dendrites were studied rather than the basal dendrites.

Why do the basal dendrites exhibit plasticity while the apical dendrites do not? A possible explanation may lie in their different inputs. Basal dendrites tend to receive feedforward sensory input from layer 4 and to some extent directly from the thalamus (White, 1978; Petreanu et al., 2009; Hooks et al., 2011; Mao et al., 2011). Apical dendrites tend to receive feedback connections from other cortical areas, including motor cortex (Petreanu et al., 2009). Therefore, sensory deprivation is more likely to affect feedforward connections onto basal dendrites, whereas motor tasks are more likely to affect feedback connections onto apical dendrites. In favor of this theory, apical dendritic plasticity does occur in motor tasks requiring mice to move their whiskers accurately to receive a reward (Kuhlman et al., 2014).

One further level of dendritic specialization was observed in this study. We found that new spine formation tended to be greater following whisker deprivation at dendritic branches with a naturally higher basal turnover rate, confirming findings of Yang et al. (2014). This suggests that, even among basal dendrites, some are primed to undergo plasticity and some are not.

\section{Dual-component structural plasticity}

CWD causes potentiation of spared whisker responses and depression of deprived whisker responses (Wallace and Fox, 1999b). Spared whisker potentiation correlates with an increase in NPSs, but also a small but significant increase in spine head size of the stable (AP) spine population. Most layer $2 / 3$ neurones in the barrel cortex receive multiwhisker input (Armstrong-James and Fox, 1987) and therefore, theoretically, only need to strengthen preexisting synapses rather than to create new ones. Nevertheless, new spines are produced and, since they stabilize over a period of 2 weeks, are thought to make functional synapses (Knott et al., 2006). It is therefore likely that NPSs represent the second component of the dual-component structural plasticity mechanism. Neither AP enlargement nor NPS formation is present in the $\alpha C a M K I I-T 286 A$ mutants, which also lack experience-dependent potentiation (Glazewski et al., 2000) and cortical LTP (Hardingham et al., 2003), providing further evidence that functional plasticity depends on the observed structural plasticity. A similar conclusion on NPS formation has been reached previously for CWD-induced potentiation of spared whisker responses and layer 5IB apical dendrites in barrel cortex (Wilbrecht et al., 2010); however, we believe that the CaMKII autophosphorylation-dependent AP spine enlargement is an entirely new observation.

\section{The effect of intrinsic spine fluctuations}

Within the stable spine population, we found that smaller spines increased and the larger spines tended to decrease in size between time points. This provides a self-regulatory homeostatic response to potentiation. Spine fluctuation analysis shows that spine sizes tend to spontaneously change this way in the absence of overt Hebbian processes to direct changes in spine size (Yasumatsu et al., 2008) and indeed lead to the log-normal spine head size distribution observed here and in other studies (Loewenstein et al., 
A

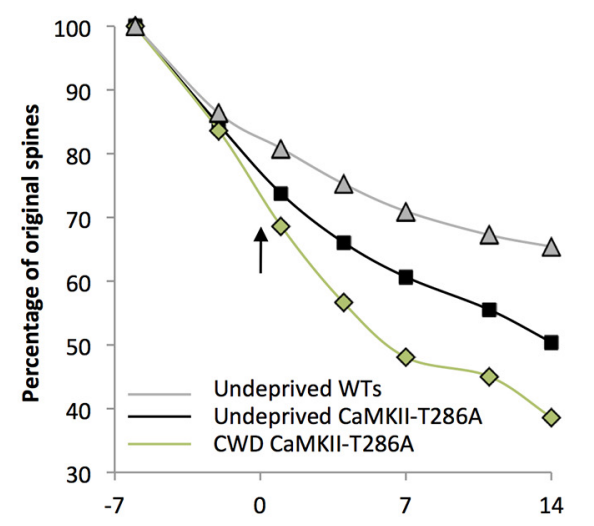

Time relative to the start of deprivation (days)

C

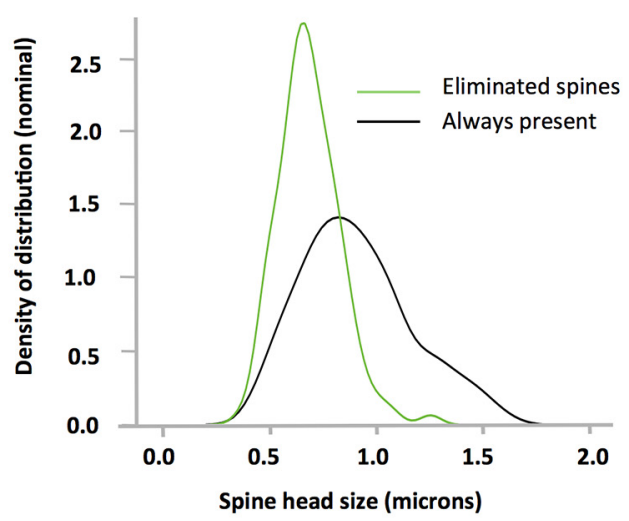

E

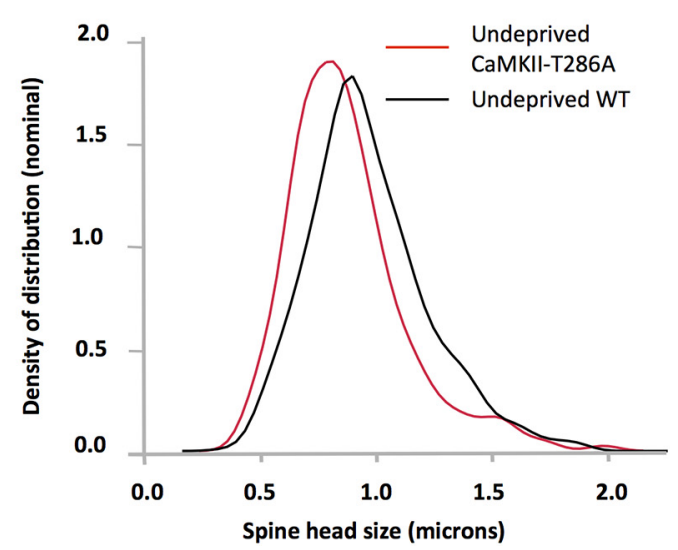

B

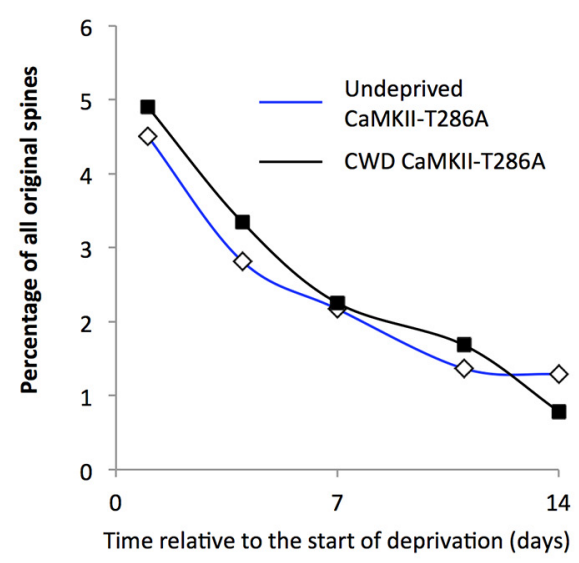

D

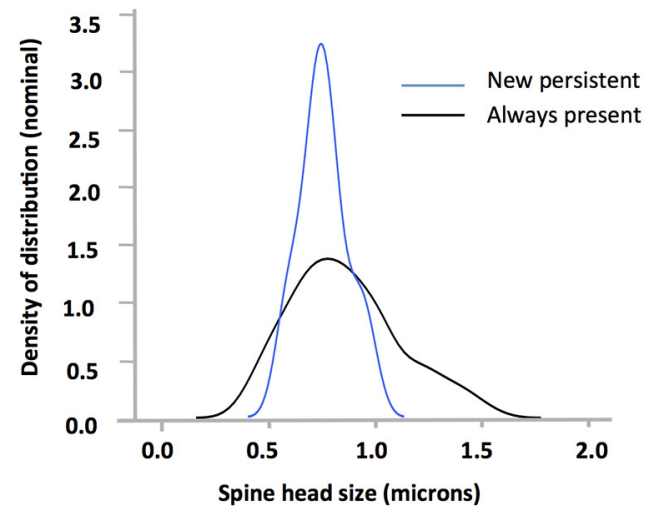

$\mathbf{F}$

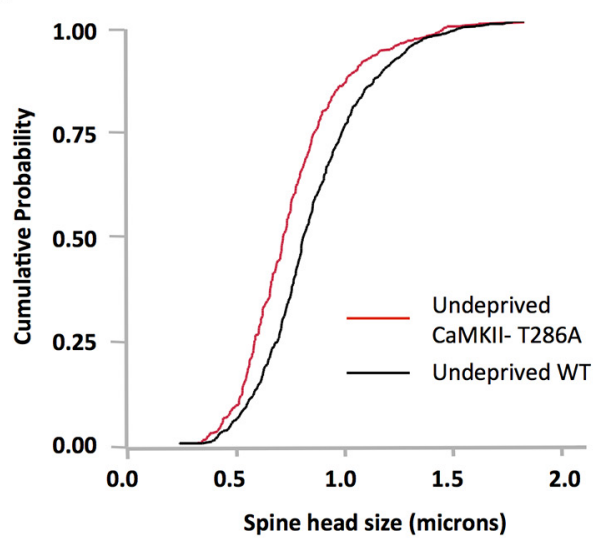

Figure 10. Effect of chessboard whisker deprivation and the $\alpha$ CaMKII-T286A genotype on lifetime of newly formed and already present spines. $\boldsymbol{A}$, The survival fraction plot shows that spine lifetimes are briefer in $\alpha$ CaMKII-T286A mice (black line) compared with WTs (gray line). CWD decreases spine survival further in $\alpha$ CaMKII-T286A mice (green line). $\boldsymbol{B}$, Newly formed spines show similar persistence in chessboard-deprived and undeprived $\alpha$ CaMKII-T286A mice. C, The distribution of spine head sizes is smaller for spines eliminated at the next time point (green line) compared with stable spines (black line). D, Newly formed spines that persist (blue line) have a similar spine size distribution to that of stable spines (black line) in $\alpha$ CaMKII-T286A mice. E, Spine head sizes are smaller in $\alpha$ CaMKII-T286A mice (red) compared with WTs (black); data for undeprived animals. $\boldsymbol{F}$, Cumulative distribution function for data shown in $\boldsymbol{E}$. Spines are summed for all cases within each group to form the decay curves.

2011). Theoretical studies have shown that Hebbian processes combined with random spine fluctuations create an intrinsically homeostatic system (Matsubara and Uehara, 2016).

The increase in size of the stable spine population following CWD is reminiscent of a TNF- $\alpha$-dependent homeostatic increase in spine size seen in dendrites that show elevated spine elimination (Barnes et al., 2017). However, two arguments suggest that the size increase we saw is not homeostatic: (1) because the AP spine enlargement occurs against a background of increased spine formation rather than a loss of spines, which suggests that there is no loss for the homeostatic mechanism to compensate; and (2) the AP spine enlargement was absent in the $\alpha$ CaMKII-T286A point mutants, which lack LTP but not TNF- $\alpha$ dependent homeostatic plasticity (Greenhill et al., 
A

Effect of deprivation pattern on spine size

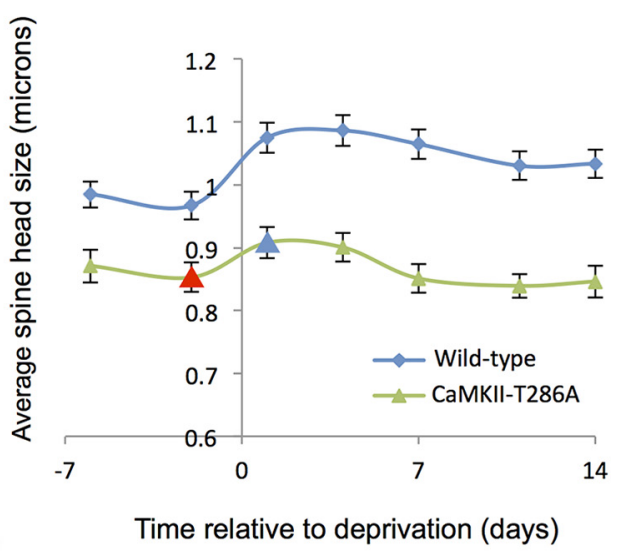

C Trajectories of individual spine size changes

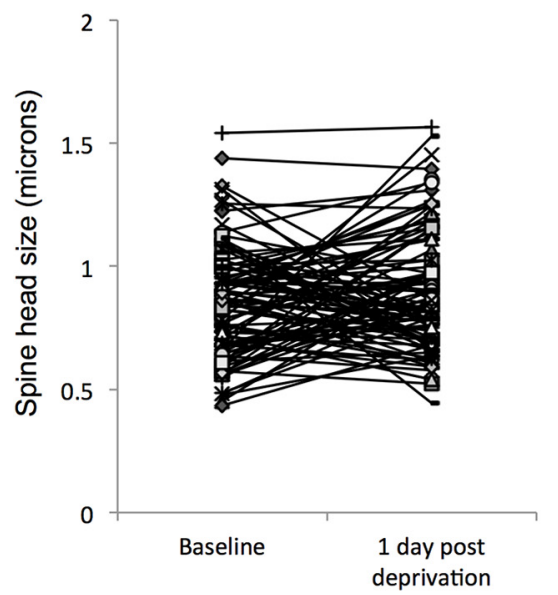

B

Spine size distribution before and after Deprivation CaMKII-T286A

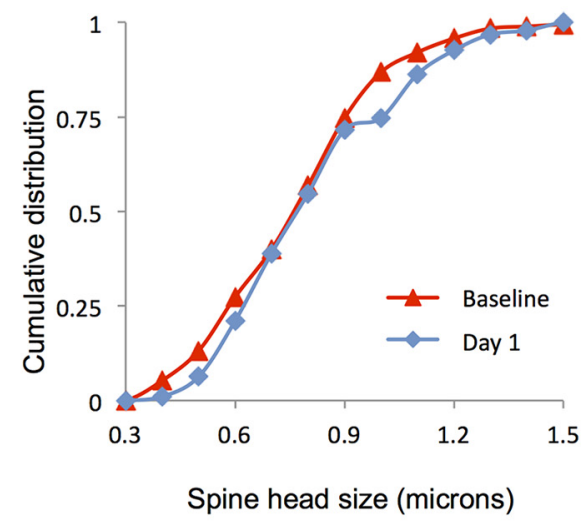

D Change in spine size by original size

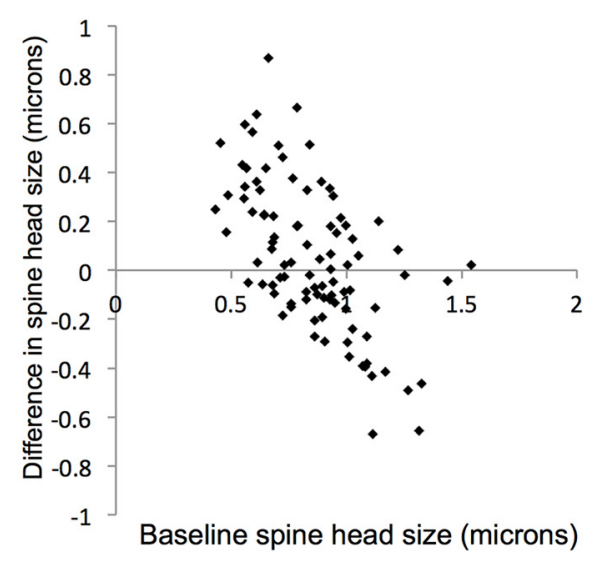

Figure 11. The effect of deprivation pattern on spine size of the stable spine population in $\alpha$ CaMKII-T286A mice. $A$, CWD leads to an increase in the average spine head size in the stable spine population in WTs (blue line) but not in the $\alpha$ CaMKII-T286A mutants (green line). $\boldsymbol{B}$, In $\alpha$ CaMKII-T286A mutants, the cumulative distribution functions of spine head size overlap for the stable spine population before (red line) and after CWD (blue). C, Trajectories of individual spine size changes between baseline and $1 \mathrm{~d}$ post chessboard deprivation. D, For the stable population, small spine heads tend to increase in size and large spine heads decrease in $\alpha$ CaMKII-T286A mice, but the overlap in sizes increasing and decreasing is greater in $\alpha$ CaMKII-T286A mice than with WTs (compare with Fig. 9F). D, Data are for the same population in $\boldsymbol{B}$ and $\boldsymbol{C}$.

2015). This suggests that AP spine enlargement is related to Hebbian addition and input-specific potentiation rather than a homeostatic mechanism. This fits with the neurophysiological effect of chessboard deprivation, which is to increase selectively the spared whisker responses rather than homeostatically increase whisker responses in general (Wallace and Fox, 1999b; Hardingham et al., 2008).

\section{The role of CaMKII in structural plasticity}

Spine heads fluctuate in size independent of activity-driven increases and decreases in spine size (Yasumatsu et al., 2008). Consequently, spines with small heads are vulnerable to elimination from spontaneous decreases in spine size. New spines are vulnerable to elimination for this reason, and we found that they only persist if their heads grow rapidly to the population average size. Spine head size for NPSs is indistinguishable from the main population of stable spines after $24 \mathrm{~h}$ in WT mice, whereas new spines that are eliminated are smaller, like transient spines in general. Activity-dependent spine enlargement requires CaMKII (Bosch et al., 2014; Hedrick et al., 2016; Fu and Ip, 2017). The lack of CaMKII autophosphorylation in the $\alpha$ CaMKII-T286A mice presumably prevents sensory-directed spine enlargement and stabi- lization; therefore, new spines tend to be eliminated more frequently in $\alpha C a M K I I-T 286 A$ mice leading to their baseline turnover rate being $\sim 24 \%$ higher than in WTs.

In addition to the decreased persistence of new spines, we also found that new spines do not form at an elevated rate following CWD in $\alpha$ CaMKII-T286A mice. This suggests that $\alpha$ CaMKIIautophosphorylation is required for the substantial increase in new spine formation itself. In favor of this theory, it has been shown that CaMKII lies at the center of several signaling pathways in the spine head, one of which leads to production of RhoA, which can diffuse to neighboring spines and thereby affect the cytoskeleton of new and emerging spines and another that generates local BDNF synthesis, trkB signaling, and diffusion of newly activated Racl to neighboring spines with a similar effect (Hedrick et al., 2016). Both Racl and RhoA are part of the system that leads to spine enlargement via LIMk translocation to and binding of cofilin to the spine head (Bosch et al., 2014). However, it is not clear at this stage whether this system alters the dendritic cytoskeleton in such a way as to initiate new spine production, rather than increasing the probability of spontaneously occurring new spines becoming stabilized by spine head enlargement. 
We draw a number of conclusions from the present findings; first, that layer $2 / 3$ neurones do show robust structural plasticity in response to whisker deprivation; therefore, the functional plasticity we see in this layer is likely to depend on underpinning structural plasticity. Previous studies may have missed this by looking at other dendritic locations or by using an ineffective whisker deprivation method. Second, that potentiation occurs due to a dual-component enlargement of stable spines plus addition of new spines and CaMKII is central to both. While the role of CaMKII in LTP and spine enlargement is reasonably well understood, the mechanism by which it is involved in spine production is not established at present.

\section{References}

Armstrong-James M, Fox K (1987) Spatiotemporal convergence and divergence in the rat S1 "barrel" cortex. J Comp Neurol 263:265-281.

Barnes SJ, Sammons RP, Jacobsen RI, Mackie J, Keller GB, Keck T (2015) Subnetwork-specific homeostatic plasticity in mouse visual cortex in vivo. Neuron 86:1290-1303.

Barnes SJ, Franzoni E, Jacobsen RI, Erdelyi F, Szabo G, Clopath C, Keller GB, Keck T (2017) Deprivation-induced homeostatic spine scaling in vivo is localized to dendritic branches that have undergone recent spine loss. Neuron 96:871-882.e5.

Bosch M, Castro J, Saneyoshi T, Matsuno H, Sur M, Hayashi Y (2014) Structural and molecular remodeling of dendritic spine substructures during long-term potentiation. Neuron 82:444-459.

Celikel T, Szostak VA, Feldman DE (2004) Modulation of spike timing by sensory deprivation during induction of cortical map plasticity. Nat Neurosci 7:534-541.

Chang JY, Parra-Bueno P, Laviv T, Szatmari EM, Lee SR, Yasuda R (2017) CaMKII autophosphorylation is necessary for optimal integration of $\mathrm{Ca}(2+)$ signals during LTP induction, but not maintenance. Neuron 94: $800-808 . e 4$.

Chen BE, Lendvai B, Nimchinsky EA, Burbach B, Fox K, Svoboda K (2000) Imaging high-resolution structure of GFP-expressing neurons in neocortex in vivo. Learn Mem 7:433-441.

Crowe SE, Ellis-Davies GC (2014) Longitudinal in vivo two-photon fluorescence imaging. J Comp Neurol 522:1708-1727.

Dachtler J, Hardingham NR, Glazewski S, Wright NF, Blain EJ, Fox K (2011) Experience-dependent plasticity acts via GluR1 and a novel neuronal nitric oxide synthase-dependent synaptic mechanism in adult cortex. J Neurosci 31:11220-11230.

Fox K (1992) A critical period for experience-dependent synaptic plasticity in rat barrel cortex. J Neurosci 12:1826-1838.

Fox K (1994) The cortical component of experience-dependent synaptic plasticity in the rat barrel cortex. J Neurosci 14:7665-7679.

Fox K, Wong RO (2005) A comparison of experience-dependent plasticity in the visual and somatosensory systems. Neuron 48:465-477.

Fox K, Greenhill S, Haan AD (2018) Barrel cortex as a model system for understanding the molecular, structural, and functional basis of cortical plasticity. Amsterdam: Elsevier.

Fu AK, Ip NY (2017) Regulation of postsynaptic signaling in structural synaptic plasticity. Curr Opin Neurobiol 45:148-155.

Gambino F, Holtmaat A (2012) Spike-timing-dependent potentiation of sensory surround in the somatosensory cortex is facilitated by deprivation-mediated disinhibition. Neuron 75:490-502.

Giese KP, Fedorov NB, Filipkowski RK, Silva AJ (1998) Autophosphorylation at Thr286 of the alpha calcium-calmodulin kinase II in LTP and learning. Science 279:870-873.

Glazewski S, Fox K (1996) Time course of experience-dependent synaptic potentiation and depression in barrel cortex of adolescent rats. J Neurophysiol 75:1714-1729.

Glazewski S, Giese KP, Silva A, Fox K (2000) The role of alpha-CaMKII autophosphorylation in neocortical experience-dependent plasticity. Nat Neurosci 3:911-918.

Glazewski S, Greenhill S, Fox K (2017) Time-course and mechanisms of homeostatic plasticity in layers $2 / 3$ and 5 of the barrel cortex. Philos Trans R Soc Lond B Biol Sci 372:20160150.

Greenhill SD, Ranson A, Fox K (2015) Hebbian and homeostatic plasticity mechanisms in regular spiking and intrinsic bursting cells of cortical layer 5. Neuron 88:539-552.
Grutzendler J, Kasthuri N, Gan WB (2002) Long-term dendritic spine stability in the adult cortex. Nature 420:812-816.

Hardingham N, Glazewski S, Pakhotin P, Mizuno K, Chapman PF, Giese KP, Fox K (2003) Neocortical long-term potentiation and experiencedependent synaptic plasticity require alpha-calcium/calmodulin-dependent protein kinase II autophosphorylation. J Neurosci 23:4428-4436.

Hardingham N, Wright N, Dachtler J, Fox K (2008) Sensory deprivation unmasks a PKA-dependent synaptic plasticity mechanism that operates in parallel with CaMKII. Neuron 60:861-874.

Hedrick NG, Harward SC, Hall CE, Murakoshi H, McNamara JO, Yasuda R (2016) Rho GTPase complementation underlies BDNF-dependent homo- and heterosynaptic plasticity. Nature 538:104-108.

Hofer SB, Mrsic-Flogel TD, Bonhoeffer T, Hübener M (2009) Experience leaves a lasting structural trace in cortical circuits. Nature 457:313-317.

Hoffman KL, McNaughton BL (2002) Coordinated reactivation of distributed memory traces in primate neocortex. Science 297:2070-2073.

Holtmaat A, Wilbrecht L, Knott GW, Welker E, Svoboda K (2006) Experience-dependent and cell-type-specific spine growth in the neocortex. Nature 441:979-983.

Holtmaat A, Bonhoeffer T, Chow DK, Chuckowree J, De Paola V, Hofer SB, Hübener M, Keck T, Knott G, Lee WC, Mostany R, Mrsic-Flogel TD, Nedivi E, Portera-Cailliau C, Svoboda K, Trachtenberg JT, Wilbrecht L (2009) Long-term, high-resolution imaging in the mouse neocortex through a chronic cranial window. Nat Protoc 4:1128-1144.

Hooks BM, Hires SA, Zhang YX, Huber D, Petreanu L, Svoboda K, Shepherd GM (2011) Laminar analysis of excitatory local circuits in vibrissal motor and sensory cortical areas. PLoS Biol 9:e1000572.

Jacob V, Petreanu L, Wright N, Svoboda K, Fox K (2012) Regular spiking and intrinsic bursting pyramidal cells show orthogonal forms of experience-dependent plasticity in layer $\mathrm{V}$ of barrel cortex. Neuron 73: 391-404.

Josselyn SA, Frankland PW (2018) Memory allocation: mechanisms and function. Annu Rev Neurosci 41:389-413.

Keck T, Keller GB, Jacobsen RI, Eysel UT, Bonhoeffer T, Hübener M (2013) Synaptic scaling and homeostatic plasticity in the mouse visual cortex in vivo. Neuron 80:327-334.

Knott GW, Holtmaat A, Wilbrecht L, Welker E, Svoboda K (2006) Spine growth precedes synapse formation in the adult neocortex in vivo. Nat Neurosci 9:1117-1124.

Kuhlman SJ, O'Connor DH, Fox K, Svoboda K (2014) Structural plasticity within the barrel cortex during initial phases of whisker-dependent learning. J Neurosci 34:6078-6083.

Lendvai B, Stern EA, Chen B, Svoboda K (2000) Experience-dependent plasticity of dendritic spines in the developing rat barrel cortex in vivo. Nature 404:876-881.

Loewenstein Y, Kuras A, Rumpel S (2011) Multiplicative dynamics underlie the emergence of the log-normal distribution of spine sizes in the neocortex in vivo. J Neurosci 31:9481-9488.

Ma L, Qiao Q, Tsai JW, Yang G, Li W, Gan WB (2016) Experiencedependent plasticity of dendritic spines of layer $2 / 3$ pyramidal neurons in the mouse cortex. Dev Neurobiol 76:277-286.

Mao T, Kusefoglu D, Hooks BM, Huber D, Petreanu L, Svoboda K (2011) Long-range neuronal circuits underlying the interaction between sensory and motor cortex. Neuron 72:111-123.

Matsubara T, Uehara K (2016) Homeostatic plasticity achieved by incorporation of random fluctuations and soft-bounded Hebbian plasticity in excitatory synapses. Front Neural Circuits 10:42.

Miller SG, Kennedy MB (1986) Regulation of brain type II $\mathrm{Ca}^{2+}$ / calmodulin-dependent protein kinase by autophosphorylation: $\mathrm{a} \mathrm{Ca}^{2+}$. triggered molecular switch. Cell 44:861-870.

Mostany R, Portera-Cailliau C (2008) A method for 2-photon imaging of blood flow in the neocortex through a cranial window. J Vis Exp 12:678.

Oray S, Majewska A, Sur M (2006) Effects of synaptic activity on dendritic spine motility of developing cortical layer v pyramidal neurons. Cereb Cortex 16:730-741.

Petreanu L, Mao T, Sternson SM, Svoboda K (2009) The subcellular organization of neocortical excitatory connections. Nature 457:1142-1145.

Ranson A, Cheetham CE, Fox K, Sengpiel F (2012) Homeostatic plasticity mechanisms are required for juvenile, but not adult, ocular dominance plasticity. Proc Natl Acad Sci U S A 109:1311-1316. 
Rodriguez A, Ehlenberger DB, Dickstein DL, Hof PR, Wearne SL (2008) Automated three-dimensional detection and shape classification of dendritic spines from fluorescence microscopy images. PLoS One 3:e1997.

Wallace H, Fox K (1999a) Local cortical interactions determine the form of cortical plasticity. J Neurobiol 41:58-63.

Wallace H, Fox K (1999b) The effect of vibrissa deprivation pattern on the form of plasticity induced in rat barrel cortex. Somatosens Mot Res $16: 122-138$

Wallace H, Glazewski S, Liming K, Fox K (2001) The role of cortical activity in experience-dependent potentiation and depression of sensory responses in rat barrel cortex. J Neurosci 21:3881-3894.

White EL (1978) Identified neurons in mouse Sml cortex which are postsynaptic to thalamocortical axon terminals: a combined Golgielectron microscopic and degeneration study. J Comp Neurol 181: 627-661.

Wilbrecht L, Holtmaat A, Wright N, Fox K, Svoboda K (2010) Structural plasticity underlies experience-dependent functional plasticity of cortical circuits. J Neurosci 30:4927-4932.

Wright N, Glazewski S, Hardingham N, Phillips K, Pervolaraki E, Fox K (2008) Laminar analysis of the role of GluR1 in experience-dependent and synaptic depression in barrel cortex. Nat Neurosci 11:11401142.

Yang G, Pan F, Gan WB (2009) Stably maintained dendritic spines are associated with lifelong memories. Nature 462:920-924.

Yang G, Lai CS, Cichon J, Ma L, Li W, Gan WB (2014) Sleep promotes branch-specific formation of dendritic spines after learning. Science 344:1173-1178.

Yasumatsu N, Matsuzaki M, Miyazaki T, Noguchi J, Kasai H (2008) Principles of long-term dynamics of dendritic spines. J Neurosci 28:13592-13608.

Zuo Y, Yang G, Kwon E, Gan WB (2005) Long-term sensory deprivation prevents dendritic spine loss in primary somatosensory cortex. Nature 436:261-265. 